\title{
p63 and p73 coordinate p53 function to determine the balance between survival, cell death, and senescence in adult neural precursor cells
}

\author{
MP Fatt ${ }^{1,2}$, GI Cancino', FD Miller, ${ }^{\star, 1,2,3,4}$ and DR Kaplan ${ }^{\star, 1,2,4}$
}

The p53 family members p73 and p63 have been implicated in various aspects of stem cell regulation. Here, we have asked whether they work together to regulate stem cell biology, focusing upon neural precursor cells (NPCs) in the adult murine brain. By studying mice that are haploinsufficient for $p 63$ and/or p73, we show that these two proteins cooperate to ensure appropriate NPC self-renewal and long-term maintenance in the hippocampus and forebrain, and that when both are haploinsufficient, the NPC deficits are significantly greater than haploinsufficiency for either alone. We show that, in the case of $063^{+I-}$ mice, this decrease in adult NPCs is caused by enhanced apoptosis. However, when p73 is coincidently haploinsufficient, this rescues the enhanced apoptosis of $\mathrm{p} 63^{+1-}$ NPCs under both basal conditions and following genotoxic stress, instead causing increased cellular senescence. This increase in cellular senescence is likely due, at least in part, to increased levels of basal DNA damage and $\mathrm{p} 53$ activation, as genetic ablation of $\mathrm{p} 53$ completely rescues the senescence phenotype observed in $\mathrm{p} 63^{+I-} ; \mathrm{p} 73^{+l-}$ mice. Thus, the presence of $p 73$ determines whether $p 63^{+I-}$ NPCs exhibit increased p53-dependent apoptosis or senescence. Together, these studies demonstrate that $p 63$ and p73 cooperate to maintain adult NPC pools through regulation of p53 function; p63 antagonizes p53 to promote cellular survival, whereas p73 regulates self-renewal and p53-mediated apoptosis versus senescence.

Cell Death and Differentiation (2014) 21, 1546-1559; doi:10.1038/cdd.2014.61; published online 9 May 2014

In the adult mammalian brain, new neurons are constantly being generated and integrated into pre-existing circuitry. These new neurons are generated by neural precursor cells (NPCs) that reside in two specialized niches - the subgranular zone (SGZ) of the dentate gyrus in the hippocampus, and the subventricular zone (SVZ) of the lateral ventricles. ${ }^{1,2}$ In the hippocampus, NPCs from the SGZ generate mature dentate granule neurons, which aid in the process of memory formation and consolidation. In the SVZ, neuroblasts migrate into the olfactory bulb, where they differentiate into interneurons that help regulate processes such as olfactory discrimination.

Given these contributions to cognitive function, adult NPCs must be tightly regulated in terms of survival, proliferation, and self-renewal. Although many regulators of these processes have been found, very little is known about how they interact with one another to determine cellular status. One such group of regulatory proteins known to coordinate all the above processes in NPCs is the p53 family. Although studies have shown a plethora of interactions between p53 family members in both normal and pathological states, ${ }^{3-6}$ no studies have been performed examining the functional interactions of all expressed family members in adult NPCs.
The p53 family of transcription factors consists of p53, p63, and p73 with similar transactivation, DNA-binding, and oligomerization domains. For p63 and p73, alternative promoter usage generates two major isoforms, full-length and transactivation-competent (TA), and N-terminally truncated $(\Delta \mathrm{N})$ isoforms. ${ }^{7}$ These isoforms can antagonize one another, with the $\Delta \mathrm{N}$ isoforms acting in a dominant-inhibitory manner toward the TA isoforms by forming inactive oligomers or by binding to and blocking the transactivation of TA-specific transcriptional promoters. In NPCs, the three predominantly expressed p53 family members are p53, $\Delta$ Np63, and TAp73. ${ }^{4,8-14}$ p53 regulates apoptosis and proliferation of NPCs, ${ }^{8,9} \Delta$ Np63 promotes survival by antagonizing p53mediated activation of target genes such as p53-upregulated modulator of apoptosis (PUMA), ${ }^{4}$ and TAp73 promotes selfrenewal $^{10,12-14}$ by transcriptionally regulating the Hey2 gene. ${ }^{10}$ Given these diverse activities, we asked whether these family members coordinately regulate NPC biology, using mice in which one or two copies of p53, p63, or p73 genes are deleted. We show that $p 63$ and p73 interact to regulate $\mathrm{p53}$-dependent NPC apoptosis versus senescence, thereby determining appropriate adult neurogenesis.

\footnotetext{
${ }^{1}$ Program in Neuroscience and Mental Health, Hospital for Sick Children, Toronto, Ontario, Canada; ${ }^{2}$ Institute of Medical Science, Toronto, Ontario, Canada; ${ }^{3}$ Department of Physiology, University of Toronto, Toronto, Ontario, Canada and ${ }^{4}$ Department of Molecular Genetics, University of Toronto, Toronto, Ontario, Canada ${ }^{*}$ Corresponding authors: DR Kaplan or FD Miller, Neurosciences \& Mental Health, Research Institute, Hospital for Sick Children, Peter Gilgan Centre for Research and Learning, 686 Bay Street, Room 18-9715, Toronto, Ontario M5G 0A4, Canada. Tel: +416 8137654 ext. 301433; Fax: +416 813 2212; E-mail: dkaplan@ sickkids.ca or fredam@sickkids.ca

Abbreviations: NPC, neural precursor cell; SGZ, subgranular zone; SVZ, subventricular zone; PUMA, p53-upregulated modulator of apoptosis; Sox2, SRY (sex determining region Y)-box 2; BrdU, 5-bromo-2'-deoxyuridine; NeuN, neuronal nuclei (also known as Feminizing Locus on X-3, or Fox-3); CC3, cleaved caspase-3; TUNEL, terminal deoxynucleotidyl transferase dUTP nick end labeling; ZVAD-fmk, carbobenzoxy-valyl-alanyl-aspartyl-[0-methyl]-fluoromethylketone; SA- $\beta$-Gal, senescence-associated $\beta$-galactosidase; $\gamma \mathrm{H} 2 \mathrm{AX}$, phospho-histone $\mathrm{H} 2 \mathrm{~A}$, member X; RT-PCR, reverse transcriptase PCR

Received 17.10.13; revised 25.2.14; accepted 02.4.14; Edited by G Melino; published online 09.5.14
} 


\section{Results}

p63 and p73 cooperate to regulate NPCs and adult-born neurons in the hippocampus. The $\triangle \mathrm{Np} 63$ and TAp73 isoforms are necessary for NPC survival, self-renewal, and long-term maintenance in the murine brain. ${ }^{4,10,12-14}$ To ask about potential interactions between these two family members, we crossed $\mathrm{p} 63^{+/-15}$ and $\mathrm{p} 73^{+/-16}$ mice and characterized hippocampal NPCs and neurogenesis in 3-month-old $\mathrm{p} 63^{+/+} ; \mathrm{p} 73^{+/-}, \mathrm{p} 63^{+/-} ; \mathrm{p} 73^{+/+}$, and $\mathrm{p} 63^{+/-}$; $\mathrm{p} 73^{+/-}$mice. Morphological analysis showed that the hippocampus was grossly similar to wild-type mice in the heterozygous genotypes (Figure 1a). However, quantification of the thickness of the upper and lower blades of the dentate gyrus demonstrated a small but significant decrease in width in the $\mathrm{p} 73^{+/-}$and $\mathrm{p} 63^{+/-}$mice, and showed that this decrease was greater in the $\mathrm{p} 63^{+/-} ; \mathrm{p} 73^{+/-}$mice than in the single heterozygotes (Figure $1 b$ ). To ask if this was due to decreased adult NPC numbers and/or neurogenesis, we immunostained sections for the precursor marker SRY (sex determining region Y)-box 2 (Sox2; Figure 1c) or the newborn neuron marker doublecortin (Figure 1e). Quantification demonstrated that $\mathrm{p} 73^{+/-}$and $\mathrm{p} 63^{+/-}$mice had approximately $87 \%$ and $71 \%$ of the Sox2-positive NPCs seen in wild-type mice, and that this was further decreased to $59 \%$ in double heterozygotes (Figure 1d). Similar results were obtained for doublecortin-positive newborn neurons, which were significantly decreased in single heterozygotes, with a further decrease in double heterozygotes (Figure 1f).

To confirm these changes, we performed 5-bromo-2'deoxyuridine (BrdU)-labeling experiments to assess proliferating precursors; we administered BrdU to mice and 1 day later immunostained sections for BrdU (Figure 1g). There were fewer BrdU-positive SGZ precursors in $\mathrm{p} 73^{+/-}$and p $63^{+/-}$mice, and numbers were further decreased to $50 \%$ of wild-type levels in double heterozygotes (Figure 1h). To confirm that adult neurogenesis was decreased, we injected 2-month-old mice with BrdU and 30 days later quantified BrdU-positive dentate gyrus cells expressing the mature neuron marker neuronal nuclei (NeuN; Figure 1i). $\mathrm{p} 63^{+/-}$and $\mathrm{p} 73^{+/-}$mice both had significantly fewer adult-born neurons than wild-type mice, and $\mathrm{p} 63^{+/-} ; \mathrm{p73} 3^{+/-}$mice had less than $50 \%$ of wild-type levels (Figure 1j). Thus, p63 and p73 are individually important for adult hippocampal neurogenesis, as previously reported, ${ }^{4,10,12-14}$ and haploinsufficiency for both causes greater deficits than haploinsufficiency for either gene alone.

p63 and p73 cooperate to regulate SVZ NPCs and adultborn neuron numbers in the olfactory bulb. To ask if p63 and p73 were generally important for adult NPCs, we examined the forebrain SVZ, the second major adult NPC niche. Mice were injected with BrdU and proliferating, BrdUpositive SVZ cells were quantified 1 day later (Figure 2a). $\mathrm{p} 63^{+/}$mice had significantly fewer proliferating NPCs than wild types (Figure 2b) and this was further decreased to $66 \%$ of wild-type levels by coincident haploinsufficiency for p73 (Figure 2b). We confirmed that proliferating precursors were decreased by immunostaining sections for the pan-precursor marker Sox2 and the proliferation marker Ki67 (Figure 2c). The proportion of Sox2-positive SVZ precursors that were also Ki67 positive was decreased in individual heterozygotes, and further decreased to $58 \%$ of wild-type levels in double heterozygotes (Figure 2d).

To determine whether total SVZ NPC numbers were also reduced, we characterized SVZ neurosphere-initiating cells (Figure 2e), a surrogate measure for the in vivo NPC pool. p $73^{+/-}$and wild-type mice had similar numbers of neurosphere-initiating cells, and this was reduced to $64 \%$ and $50 \%$, respectively, in the $\mathrm{p} 63^{+/-}$and $\mathrm{p} 63^{+/-} ; \mathrm{p} 73^{+/-} \mathrm{SVZ}$ (Figure 2f). In addition, there was a modest but significant decrease in the size of these neurospheres (Figure $2 \mathrm{~g}$ ). We also asked about self-renewal by passaging the primary neurospheres under clonal conditions. All heterozygous genotypes were deficient in self-renewal relative to wild types, with the double heterozygotes showing the greatest deficit, $56 \%$ of wild-type numbers (Figure $2 \mathrm{~h}$ ). This large deficit in selfrenewal was not due to deregulation of p53 transcription in the double-heterozygotes, as p53 mRNA levels were approximately equal to those in wild-type neurospheres (Supplementary Figure 1).

To ask whether these decreases in adult SVZ NPCs resulted in decreased neurogenesis, we examined the olfactory bulb. Initially, we Nissl stained sections, and quantified the density of granule cells, as this is decreased when adult olfactory neurogenesis is disrupted..$^{17}$ Neuronal density was significantly decreased in the $\mathrm{p} 63^{+/-} ; \mathrm{p} 73^{+/-}$ olfactory bulb relative to controls and to the single heterozygotes (Figures $3 a$ and $b$ ). To ask whether this was due to decreased adult neurogenesis, we injected mice with BrdU and quantified BrdU-positive, NeuN-positive olfactory neurons 1 month later (Figures $3 \mathrm{c}$ and d). All heterozygote groups had fewer adult-born neurons than wild types, with the lowest number (35\%) in the $\mathrm{p} 73^{+/-} ; \mathrm{p} 63^{+/-}$olfactory bulb. We also asked about different neuronal subpopulations by immunostaining similar sections for BrdU and calretinin and tyrosine hydroxylase, two subpopulation markers (Figure 3e). Adult-born calretinin and tyrosine hydroxylase-positive neurons were decreased in number in all heterozygote groups, with the largest decrease in the $\mathrm{p} 63^{+/-} ; \mathrm{p} 73^{+/-}$olfactory bulbs (Figure 3f).

p63 haploinsufficiency causes increased NPC apoptosis in vivo, and this is reversed by coincident haploinsufficiency for p73. We recently showed that haploinsufficiency for p63 causes apoptosis of adult NPCs and newborn neurons. ${ }^{4}$ To ask if the decrease in adult NPCs in $\mathrm{p} 63^{+/-}$; $\mathrm{p} 73^{+/-}$mice was also due to increased apoptosis, we immunostained dentate gyrus sections for Sox2 and the apoptosis marker cleaved caspase-3 (CC3; Figure 4a). This analysis showed that the proportion of CC3-positive, Sox2positive precursors was similar in the wild-type and $\mathrm{p} 73^{+/-}$ dentate gyrus, and, as we recently reported, ${ }^{4}$ was robustly increased in $\mathrm{p} 63^{+I-}$ mice (Figure 4b). However, this latter increase was completely reversed by coincident haploinsufficiency for $\mathrm{p} 73$ so that apoptotic precursor numbers were similar in the $\mathrm{p} 63^{+/-} ; \mathrm{p} 73^{+/-}$and wild-type dentate gyrus (Figure 4b). Similar results were obtained when we analyzed 
a

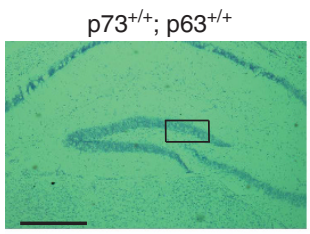

$\mathrm{p} 73^{+/+} ; \mathrm{p} 63^{+/-}$

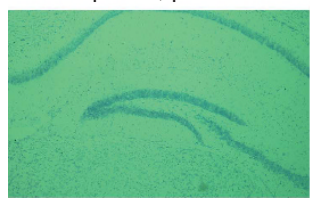

C

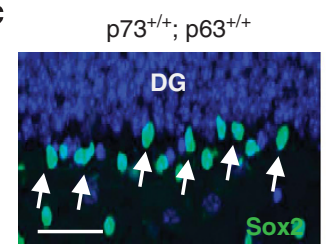

e

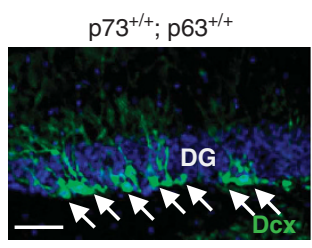

g

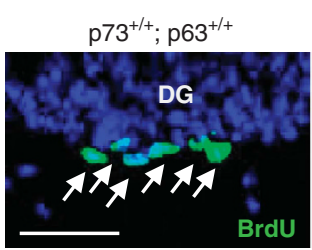

i

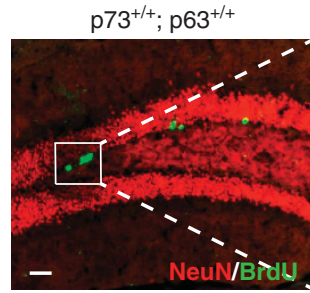

$\mathrm{p} 73^{+/-} ;{\mathrm{p} 63^{+/+}}^{+/ 2}$

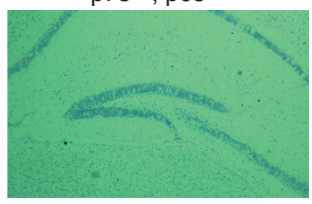

$\mathrm{p} 73^{+/-} ; \mathrm{p} 63^{+/-}$
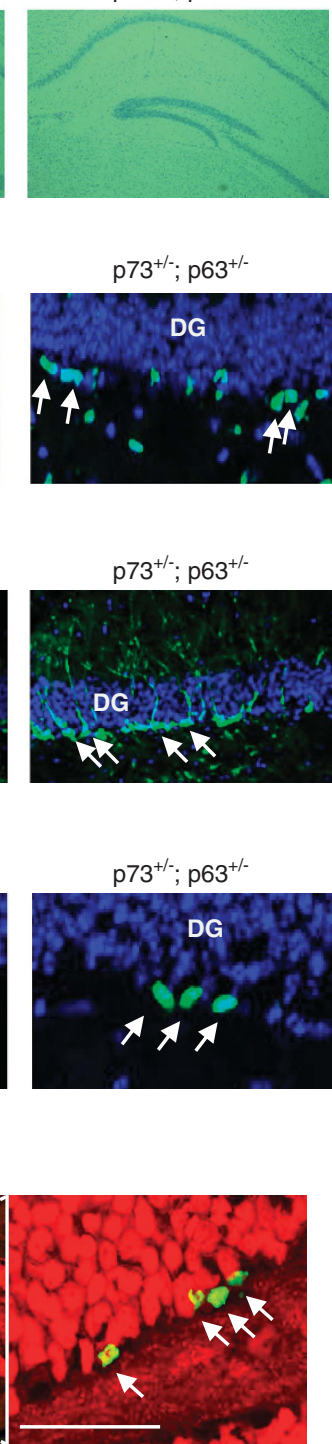

b

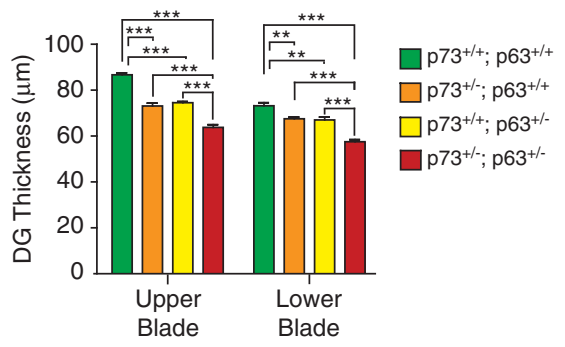

d

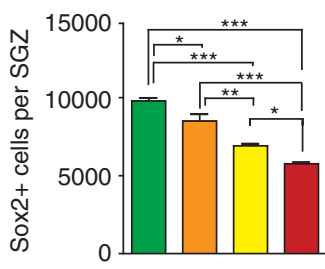

$\mathrm{p} 73^{+/+} ; \mathrm{p} 63^{+/+}$

$\square \mathrm{p} 73^{+/-} ; \mathrm{p} 63^{+/+}$

$\square \mathrm{p} 73^{+/+} ; \mathrm{p} 3^{+/}$

$\square \mathrm{p} 73^{+/-} ; \mathrm{p} 63^{+/-}$

\section{f}

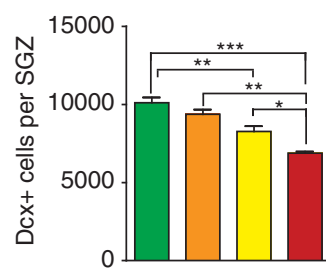

h

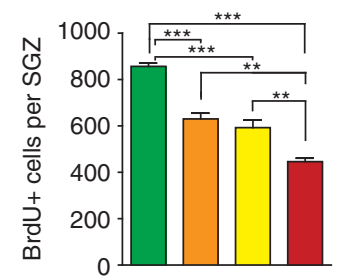

j

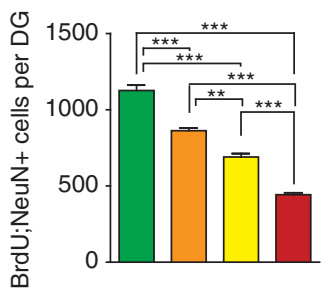

$\square \mathrm{p} 73^{+/+} ; \mathrm{p} 63^{+/+}$

$\square \mathrm{p} 73^{+/-} ; \mathrm{p}^{+/ /+}$

$\square$ p73 $3^{+/+} ; \mathrm{p} 3^{+/-}$

$\square \mathrm{p} 73^{+/-}$; $63^{+/-}$

Figure 1 Adult $p 63^{+/-} ; p 73^{+1-}$ mice display reduced hippocampal neurogenesis. The hippocampus and dentate gyrus (DG) subgranular zone (SGZ) of 3-month-old wild-type $\left(\mathrm{p} 73^{+1+} ; \mathrm{p} 63^{+1+}\right),{\mathrm{p} 73^{+/-}}_{\mathrm{p} 63^{+/+}}, \mathrm{p} 73^{+1+} ; \mathrm{p} 63^{+/-}$, and $\mathrm{p} 63^{+/-} ; \mathrm{p} 73^{+/-}$mice were analyzed for adult NPCs and adult-born neurons. (a) Micrographs of representative Nissl-stained coronal hippocampal sections from all four genotypes. Scale bar $=500 \mu \mathrm{m}$. The black box denotes the approximate region of the DG that is shown in c, e, and g. (b) Quantification of the thickness of the upper and lower DG blades as measured from sections similar to those shown in $\mathbf{a}$. ${ }^{* *} P<0.01,{ }^{* \star *} P<0.001$, $n=3$ per genotype. (c) Confocal micrographs of coronal sections through the DG of wild-type and double heterozygous mice immunostained for Sox2 showing positively stained cells throughout the SGZ. Arrows indicate positive cells. Sections were counterstained with Hoechst 33258 (blue) to identify nuclei. Scale bar $=48 \mu \mathrm{m}$. (d) Quantification of total relative Sox2-positive SGZ cells as determined from sections similar to those in c. ${ }^{*} P<0.05,{ }^{* \star} P<0.01,{ }^{* \star *} P<0.001, n=3$ per genotype. (e) Confocal micrographs of coronal sections through the DG of wild-type and double heterozygous mice immunostained for doublecortin (Dcx) showing positive cells throughout the SGZ. Arrows indicate positive cells. Sections were counterstained with Hoechst 33258 (blue) to identify nuclei. Scale bar $=48 \mu \mathrm{m}$. (f) Quantification of total relative doublecortin-positive cells in the SGZ as determined from sections similar to those in $\mathbf{e} .{ }^{*} P<0.05,{ }^{* \star} P<0.01,{ }^{* \star *} P<0.001, n=3$ per genotype. (g) Confocal micrographs of coronal sections through the DG immunostained for BrdU $24 \mathrm{~h}$ following BrdU injection. Arrows indicate positive cells. Sections were counterstained with Hoechst (blue). Scale bar $=38 \mu \mathrm{m}$. (h) Quantification of the total relative number of BrdU-positive cells in the SGZ, as determined from sections similar to those shown in $\mathbf{g}$. ${ }^{\star \star} P<0.01$, ${ }^{\star \star \star} P<0.001$, $n=3$ per genotype. (i) Representative confocal micrographs of a coronal section through the DG of a wild-type mouse injected with BrdU at 2 months of age, and then immunostained 1 month later for BrdU (green) and NeuN (red). The boxed area in the left panel is shown at higher magnification in the right panel. Arrows denote doublepositive cells. Scale bar $=50 \mu \mathrm{m}$. (j) Quantification of the total relative number of BrdU-positive, NeuN-positive cells in the DG, as determined from sections similar to that in i. ${ }^{\star \star} P<0.01,{ }^{* \star} P<0.001, n=3$ per genotype 
a

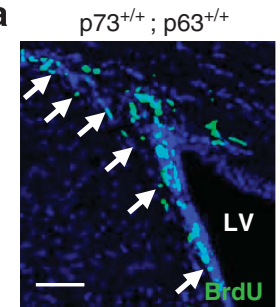

C

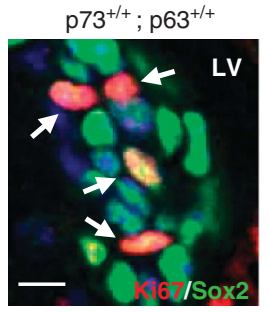

e

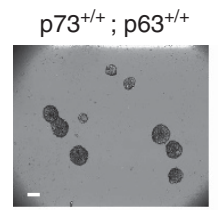

$\mathrm{p} 73^{+/+} ; \mathrm{p} 63^{+/-}$

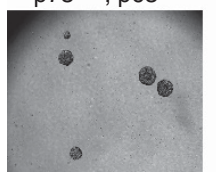

$\mathrm{p} 73^{+/-} ; \mathrm{p} 63^{+/-}$

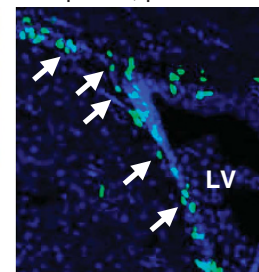

$\mathrm{p} 73^{+/-} ; \mathrm{p} 63^{+/-}$
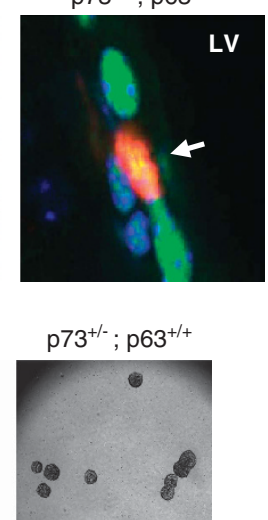

$\mathrm{p} 73^{+/-} ; \mathrm{p} 63^{+/-}$

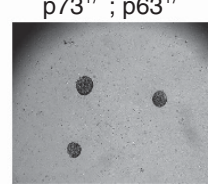

g

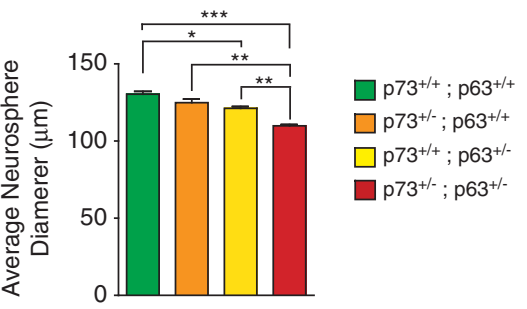

b

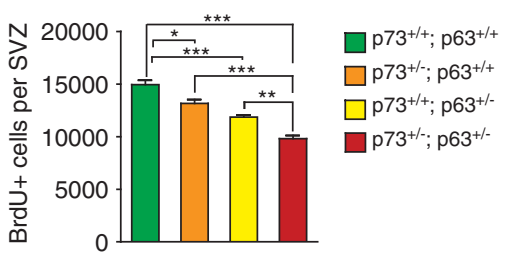

d

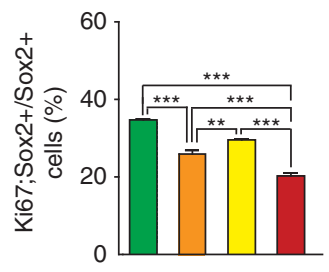

$\square \mathrm{p} 73^{+/+} ; \mathrm{p} 63^{+/+}$

$\square \mathrm{p} 73^{+/-} ;{\mathrm{p} 63^{+/+}}^{+/ 2}$

$\square \mathrm{p} 73^{+/+} ; \mathrm{p} 63^{+/-}$

$\square \mathrm{p} 73^{+/-} ; \mathrm{p}^{2} 3^{+/-}$ f

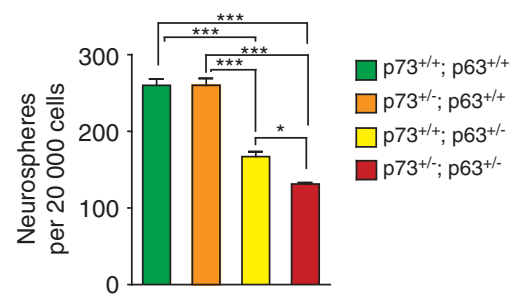

n

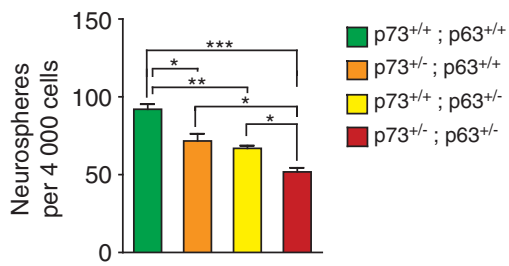

Figure 2 The $p 63^{+I-} ; p 73^{+1-}$ SVZ contains fewer neural precursors than single heterozygotes. The SVZ of 3-month-old wild-type $\left(p 73^{+/+} ; p 63^{+/+}\right), p 73^{+/-}$; $\mathrm{p} 63^{+1+}, \mathrm{p} 73^{+1+} ; \mathrm{p} 63^{+/-}$, and $\mathrm{p} 63^{+1-} ; \mathrm{p} 73^{+1-}$ mice were analyzed for NPCs. (a) Confocal micrographs of representative coronal sections through the lateral ventricles immunostained for BrdU (green) $24 \mathrm{~h}$ after BrdU injection. Sections were counterstained with Hoechst (blue). Arrows denote positive cells, and LV indicates the lateral ventricle. Scale bar $=58 \mu \mathrm{m}$. (b) Quantification of the total relative number of BrdU-positive cells in the SVZ, analyzed from sections as in a. ${ }^{*} P<0.05,{ }^{* *} P<0.01$, ${ }^{* * \star} P<0.001, n=3$ per genotype. (c) Representative confocal micrographs of coronal sections through the SVZ immunostained for Sox2 (green) and Ki67 (red). Sections were counterstained with Hoechst (blue). Arrows denote double-positive cells and LV the lateral ventricle. Scale bar $=7 \mu \mathrm{m}$. (d) Quantification of the proportion of Sox2positive cells that were also positive for Ki67, as an index of proliferating NPCs, determined by counting all cells in 10 sections/mouse similar to those in $\mathbf{c}$. ${ }^{* *} P<0.01$, ${ }^{* * *} P<0.001, n=3$ per genotype. (e) Representative micrographs of primary neurospheres cultured from the SVZ of adult mice of different genotypes. Scale bar $=200 \mu \mathrm{m}$. (f) Quantification of primary neurospheres after 6 days of culture. Three mice per genotype were analyzed, and neurospheres from each mouse were cultured in triplicate wells. ${ }^{*} P<0.05$, ${ }^{* * *} P<0.001$. (g) Quantification of the average diameter of primary neurospheres from all four genotypes after 6 days in culture, as shown in $\mathbf{e}$. Three mice per genotype were analyzed, and neurospheres from each mouse were cultured in triplicate wells. ${ }^{*} P<0.05,{ }^{* \star} P<0.01,{ }^{* * *} P<0.001$. (h) Quantification of the number of secondary neurospheres 4 days after passaging. Neurospheres were cultured in triplicate wells, and three mice were analyzed per genotype. ${ }^{*} P<0.05,{ }^{* *} P<0.01$, ${ }^{* * \star} P<0.001$

newborn neurons; haploinsufficiency for p73 rescued the increase in CC3-positive, doublecortin-positive cells seen in the $\mathrm{p} 63^{+/-}$dentate gyrus (Figures $4 \mathrm{c}$ and $\mathrm{d}$ ). To confirm these results, we quantified the number of terminal deoxynucleotidyl transferase dUTP nick end labeling (TUNEL)positive NPCs (Figure 4e). The proportion of cells positive for TUNEL and Sox2 was similar between wild-type, $\mathrm{p} 73^{+/-}$, and $\mathrm{p} 63^{+/-} ; \mathrm{p} 73^{+/-}$dentate gyri, with a significant increase of over 3.5-fold in the p63 $3^{+/}$hippocampus (Figure 4f), consistent with our previous results. ${ }^{4}$

One potential explanation for these data is that haploinsufficiency for both p63 and p73 causes apoptosis at an earlier time point than seen in the $\mathrm{p} 63^{+/-}$mice. We therefore performed similar analyses of the dentate gyrus at 6 weeks of age. Immunostaining showed that the number of Sox2-positive NPCs was similar between all genotypes 
a

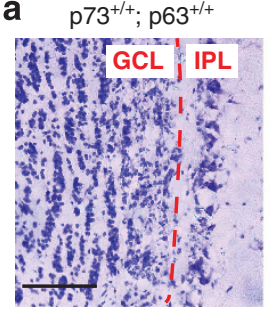

C $\mathrm{p} 73^{+/+} ; \mathrm{p} 63^{+/+}$

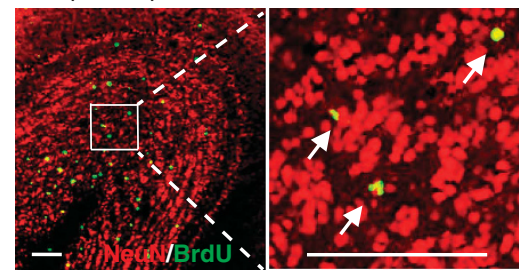

b

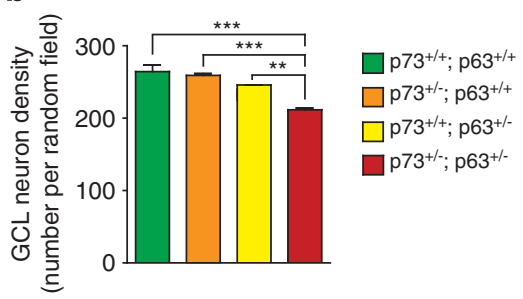

d

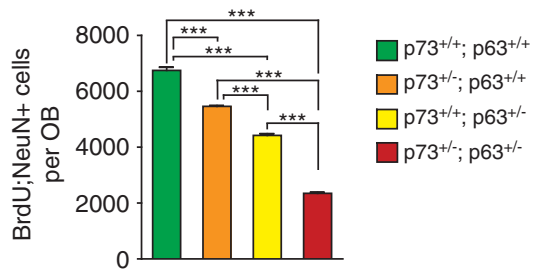

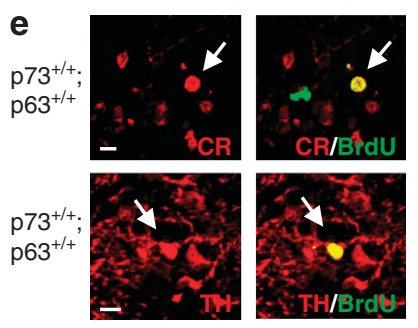

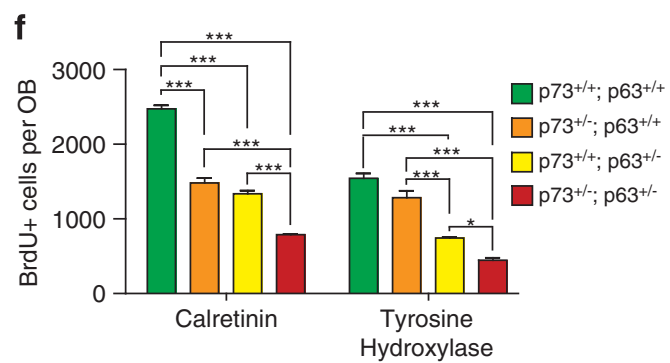

Figure 3 The $\mathrm{p} 63^{+/-} ; \mathrm{p} 73^{+/-}$olfactory bulb contains fewer adult-born neurons relative to single heterozygotes. The olfactory bulbs of 3-month-old wild-type $\left(\mathrm{p} 73^{+/+}\right.$; $\left.\mathrm{p} 63^{+1+}\right), \mathrm{p} 73^{+1-} ; \mathrm{p} 63^{+1+}, \mathrm{p} 73^{+1+} ; \mathrm{p} 63^{+1-}$, and $\mathrm{p} 63^{+1-} ; \mathrm{p} 73^{+1-}$ mice were analyzed for adult-born neurons. (a) Representative micrographs of Nissl-stained coronal sections through the olfactory bulb of wild-type and double heterozygote mice. The red dotted line indicates the border between the granule cell layer (GCL) and the internal plexiform layer (IPL). Scale bar $=100 \mu \mathrm{m}$. (b) Quantification of neuronal density in the GCL, analyzed from sections similar to those in $\mathbf{a}$. ${ }^{* \star} P<0.01,{ }^{* \star *} P<0.001$, $n=3$ per genotype. (c) Representative confocal micrographs of a coronal section through the olfactory bulb of a wild-type mouse injected with BrdU at 2 months of age and immunostained for BrdU (green) and NeuN (red) 1 month later. The boxed area in the left panel is shown in higher magnification in the right panel. Arrows denote doublepositive cells. Scale bar $=100 \mu \mathrm{m}$. (d) Quantification of the total relative number of BrdU, NeuN-positive cells throughout the entire olfactory bulb, determined from sections as in $\mathbf{c} .{ }^{* * *} P<0.001, n=3$ per genotype. (e) Confocal micrographs of coronal sections through the olfactory bulbs of wild-type mice injected with BrdU as in $\mathbf{c}$ and immunostained for BrdU (green) and either calretinin (CR, red, top panels) or tyrosine hydroxylase (TH, red, bottom panels). Arrows denote double-positive cells. Scale bar $=7 \mu \mathrm{m}$. (f) Quantification of the total relative number of BrdU-positive cells that were also positive for CR or TH throughout the entire olfactory bulb, determined from sections as in e. ${ }^{*} P<0.05,{ }^{* *} P<0.001, n=3$ per genotype

(Figure 4g), as was the proportion of Sox2-positive precursors that were positive for CC3 (Figure 4h). In contrast, although doublecortin-positive newborn neuron numbers were similar in wild-type, $\mathrm{p} 63^{+1-}$ and $\mathrm{p} 73^{+1-}$ hippocampi, newborn neurons were already decreased in the double heterozygotes (Figure 4i). However, in spite of this, the proportion of CC3positive newborn neurons was similar between all genotypes (Figure 4j).

p73 haploinsufficiency inhibits basal and DNA damageinduced apoptosis in cultured $\mathrm{p}^{63^{+/-}}$NPCs. These in vivo studies suggest that distinct mechanisms underlie the depletion of NPCs in $\mathrm{p} 63^{+/-}$and $\mathrm{p} 63^{+/-} ; \mathrm{p} 73^{+/-}$mice, and that haploinsufficiency for p73 somehow rescues the NPC apoptosis in $163^{+/-}$mice. To investigate the mechanism, we turned to cultured SVZ neurospheres. Initially, we asked whether the deficits in sphere formation seen with loss of one allele of p63 and/or p73 (Figures 2e-h) could be rescued by inhibiting apoptosis. To do this, we used the general caspase inhibitor carbobenzoxy-valylalanyl-aspartyl-[O-methyl]-fluoromethylketone (ZVAD-fmk), after confirming that it rescued apoptosis of wild-type neurosphere cells following treatment with the DNA-damaging agent camptothecin (Figure 5a). Specifically, we cultured SVZ cells under clonal neurosphere conditions with and without ZVAD-fmk and quantified neurosphere numbers 6 days later. This analysis (Figure $5 b$ ) showed that wild-type and $\mathrm{p} 73^{+/-}$primary neurosphere numbers were similar in all conditions, and that ZVAD-fmk rescued the deficit in $p 63^{+/-}$ neurosphere number, as we previously reported. ${ }^{4}$ In contrast, ZVAD-fmk could not rescue the robust decrease in $\mathrm{p} 63^{+1-} ;{\mathrm{p} 73^{+1-}}$ primary neurosphere numbers (Figure $5 \mathrm{~b}$ ).

To further explore the idea that p73 haploinsufficiency rescues the enhanced apoptosis caused by p63 heterozygosity, we induced apoptotic death acutely by exposing neurospheres of the various genotypes to camptothecin for $5 \mathrm{~h}$. Quantification of condensed apoptotic nuclei (Figure 5c) showed that camptothecin doubled the number of apoptotic 
a

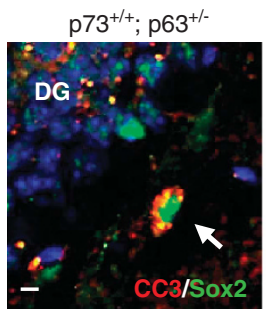

C

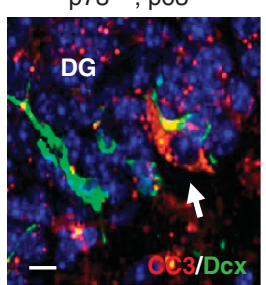

e

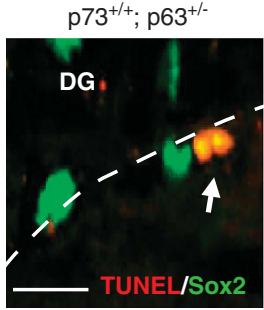

$\mathrm{p} 73^{+/-} ; \mathrm{p} 63^{+/-}$

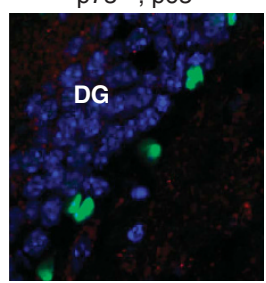

$\mathrm{p} 73^{+/-} ; \mathrm{p} 63^{+/-}$
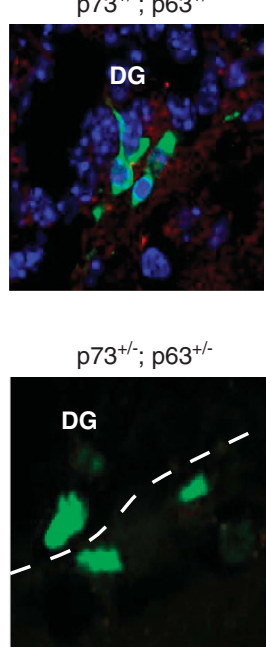

g

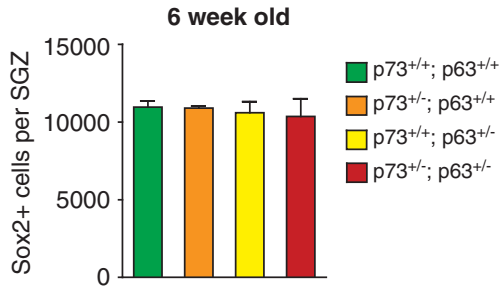

i

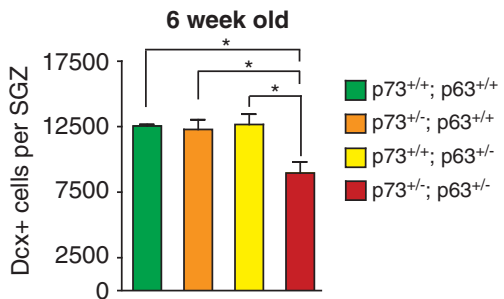

b

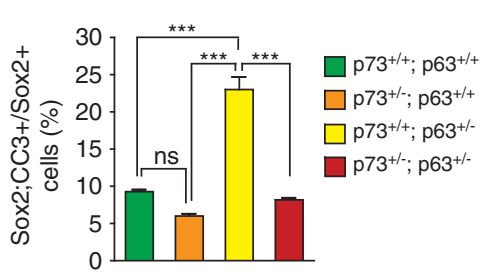

d

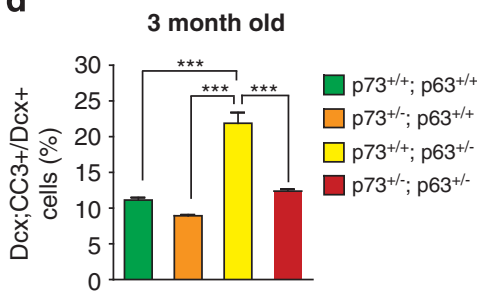

f
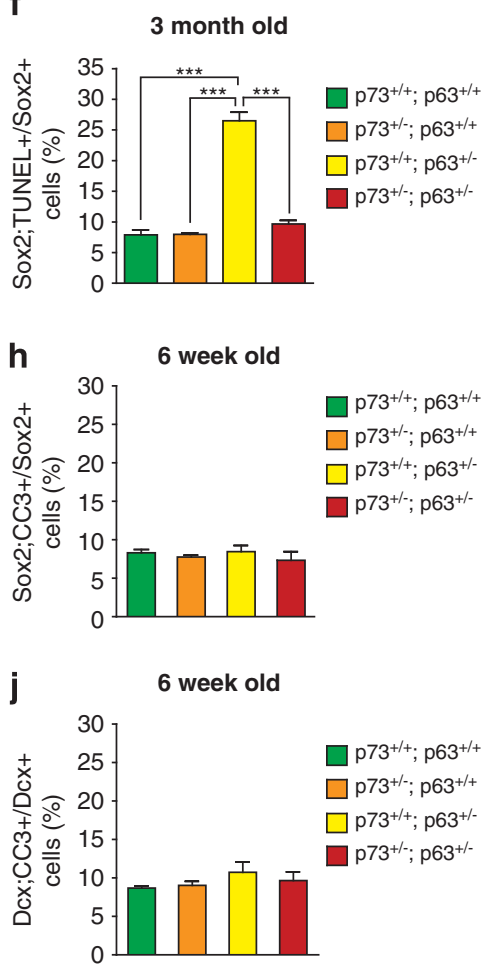

Figure 4 Coincident haploinsufficiency for p73 rescues the enhanced apoptosis of NPCs and newborn neurons in the p63 ${ }^{+/-}$dentate gyrus (DG). (a-f) The DG of 3-month-old wild-type $\left(\mathrm{p} 73^{+1+} ; \mathrm{p} 63^{+1+}\right), \mathrm{p} 73^{+1-} ; \mathrm{p} 63^{+1+}, \mathrm{p} 73^{+1+} ; \mathrm{p} 63^{+1-}$, and $\mathrm{p} 63^{+1-} ; \mathrm{p} 73^{+1-}$ mice were analyzed for apoptosis of NPCs and adult-born neurons. (a and $\mathbf{c}$ ) Confocal micrographs of coronal sections through the DG immunostained for cleaved caspase-3 (CC3, red) and either Sox2 (a, green) or doublecortin (c, green). Arrows indicate double-positive cells. Sections were counterstained with Hoechst 33258 (blue) to identify nuclei. Scale bar $=8 \mu \mathrm{m}$. (b and d) Quantification of the proportion of Sox2 (b) or doublecortin-positive (d) cells that were also positive for CC3, as determined from counting 10 sections/mouse similar to those shown in a and $\mathbf{c}$. ${ }^{* * *} P<0.001, n=3$ per genotype. (e) Confocal micrographs of coronal sections through the wild-type and double heterozygous DG labeled by TUNEL (red) and immunostained for Sox2 (green). The arrow denotes a double-positive cell, and the white hatched line indicates the DG/SGZ border. Scale bar $=14 \mu \mathrm{m}$. (f) Quantification of the proportion of Sox2-positive cells that were also TUNEL positive, as determined by counting 10 sections/mouse similar to those in $\mathbf{e} .{ }^{* *} P<0.001, n=3$ per genotype. (g-j) Coronal sections through the DG of 6-week-old wild-type, $\mathrm{p} 73^{+/-}, \mathrm{p} 63^{+/-}$, and $\mathrm{p} 63^{+/-} ; \mathrm{p} 73^{+/-}$mice were immunostained and analyzed as in a-f to determine the total relative numbers of Sox2-positive (g) and doublecortin-positive (i) cells, as well as the proportion of Sox2-positive NPCs (h) or doublecortin-positive newborn neurons (j) that were also positive for $\mathrm{CC} 3$, as determined by counting 10 coronal sections/mouse. ${ }^{*} P<0.05, n=3$ per genotype

cells in wild-type cultures, and caused an almost fourfold increase in the $\mathrm{p} 63^{+1-}$ cultures (Figure $5 \mathrm{~d}$ ). In contrast, neither the $\mathrm{p} 73^{+/-}$nor $\mathrm{p} 63^{+/-} ; \mathrm{p} 73^{+/-}$cultures displayed any increase in apoptosis following camptothecin (Figure $5 \mathrm{~d}$ ).
Similar results were obtained when we quantified the proportion of apoptotic, CC3-positive cells in these cultures (Figures 5e and f). Thus, p73 haploinsufficiency completely inhibits NPC apoptosis in response to genotoxic stress. 


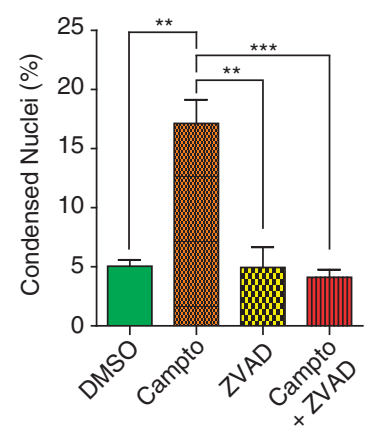

C
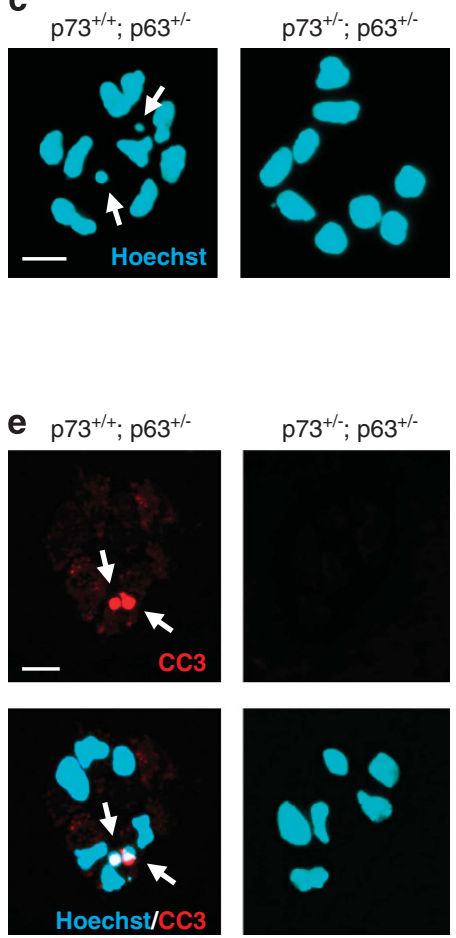

b

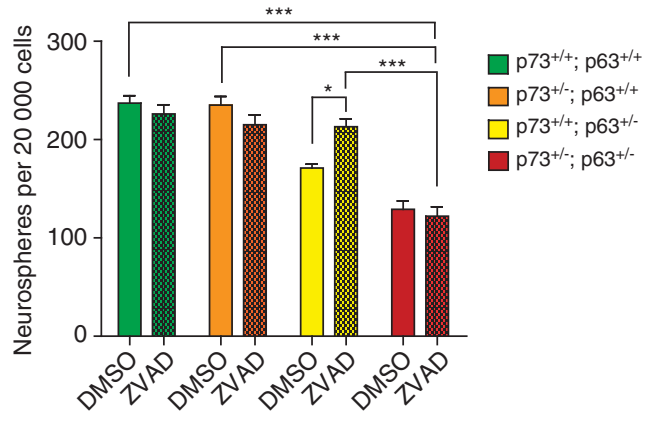

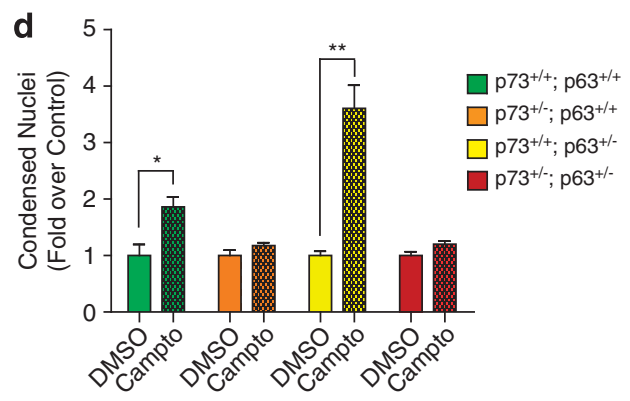

f

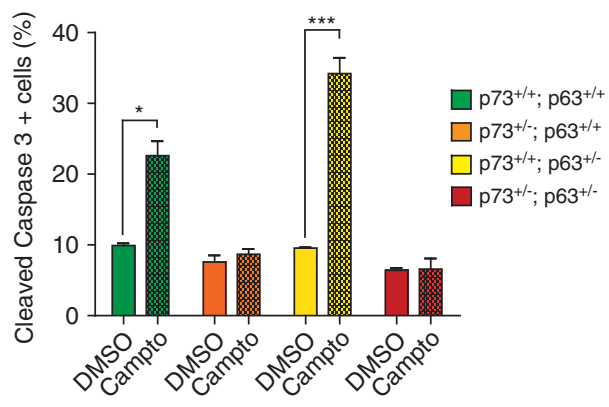

Figure 5 Adult $p 73^{+1-}$ and $p 63^{+1-} ; \mathrm{p} 73^{+/-}$SVZ NPCs are resistant to apoptosis-inducing stimuli in culture. The SVZ from 3-month-old wild-type (p73 ${ }^{+1+}$; $\left.\mathrm{p} 63^{+1+}\right), \mathrm{p} 73^{+1-} ; \mathrm{p} 63^{+1+}, \mathrm{p} 73^{+1+} ; \mathrm{p} 63^{+1-}$, and $\mathrm{p} 63^{+1-} ; \mathrm{p} 73^{+1-}$ mice was dissected and plated in neurosphere-forming conditions. (a) Primary neurospheres cultured for 6 days were treated for $5 \mathrm{~h}$ with vehicle (DMSO), $10 \mu \mathrm{m}$ camptothecin (Campto), ZVAD-fmk (ZVAD) or camptothecin plus ZVAD-fmk (Campto + ZVAD), and the percentage of apoptotic cells was determined by staining with Hoechst 33258 and counting condensed, apoptotic nuclei. ${ }^{\star \star} P<0.01,{ }^{* \star *} P<0.001, n=3$ per genotype. At least 150 cells were counted per genotype per condition. (b) SVZ cells were plated in standard medium, and vehicle (DMSO) or ZVAD-fmk (ZVAD) were added 1 day later. Neurosphere numbers were determined on day 6 . At least four mice per genotype were analyzed, and neurospheres from each mouse were cultured in triplicate wells. ${ }^{*} P<0.05,{ }^{* * *} P<0.001$. (c and d) Primary neurospheres were treated on culture day 6 with $10 \mu \mathrm{m}$ camptothecin (Campto) or vehicle (DMSO) for $5 \mathrm{~h}$, stained with Hoechst 33258 (blue, $\mathbf{c}$ ) to visualize condensed nuclei, and the proportions of condensed nuclei were determined (d). Arrows denote condensed nuclei. In $\mathbf{d}$, three mice of each genotype were analyzed in triplicate wells, and at least 150 cells were counted per genotype per condition. ${ }^{*} P<0.05,{ }^{*} P<0.01$. Scale bar $=15 \mu \mathrm{m}$. (e and f) Primary neurospheres were treated with camptothecin (Campto) or vehicle (DMSO) as in c, were stained for cleaved caspase-3 (CC3, red, top and bottom panels, e) and Hoechst 33258 (blue, bottom panels, e), and the proportion of CC3-positive cells was determined (f). Arrows in e denote CC3-positive cells. In f, three mice of each genotype were analyzed in triplicate wells, and at least 150 cells were counted per genotype per condition. ${ }^{*} P<0.05,{ }^{* \star *} P<0.001$. Scale bar $=15 \mu \mathrm{m}$

p73 haploinsufficiency switches the apoptotic response in $\mathrm{p} 63^{+1-}$ NPCs to senescence. Under conditions of DNA damage, p53 either causes apoptosis or, if that response is unavailable, cellular senescence. We therefore asked if senescence might account for the NPC deficits in $\mathrm{p} 63^{+/}$; p $73^{+1-}$ mice. To do this, we stained the adult dentate gyrus for senescence-associated $\beta$-galactosidase (SA- $\beta$-gal), a well-characterized senescence marker. Relatively few cells were SA- $\beta$-gal-positive in the wild-type and $p 63^{+/-}$SGZ
(Figures $6 a$ and b). Numbers were modestly but significantly increased in the $\mathrm{p} 73^{+/-} \mathrm{SGZ}$, and almost tripled in the ${\mathrm{p} 63^{+/-}}_{\mathrm{p}} \mathrm{p} 73^{+/-}$hippocampus (Figures $6 \mathrm{a}$ and b). To confirm that this was senescence, we immunostained sections for both Sox2 and p16 ink4a, a second marker of senescent cells (Figure $6 \mathrm{c}$ ). In the wildtype and $\mathrm{p} 63^{+/-}$dentate gyrus, approximately $20 \%$ of Sox2-positive NPCs expressed detectable p16 ink4a (Figure 6d). We also observed some $\mathrm{p} 16^{\text {ink4a }}$-positive, 
a
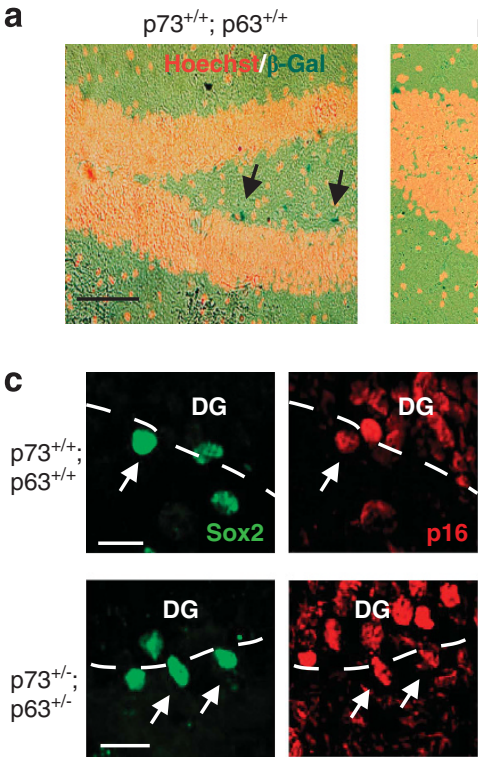

e

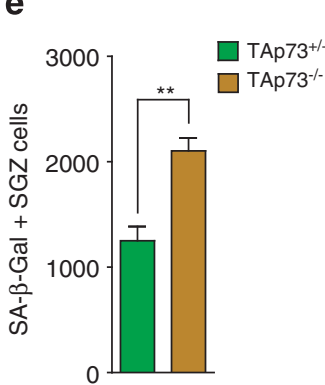

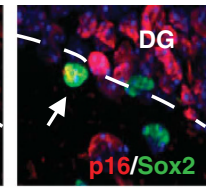

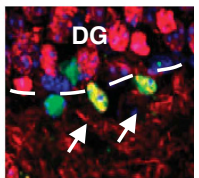

$\mathrm{p} 73^{+/-} ; \mathrm{p} 63^{+/-}$

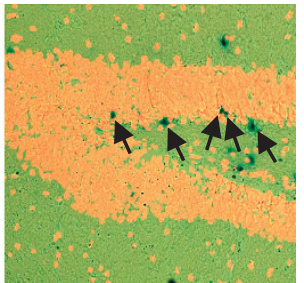

f

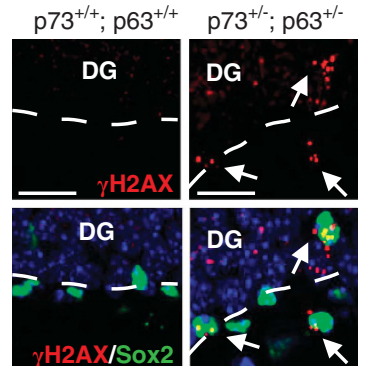

b

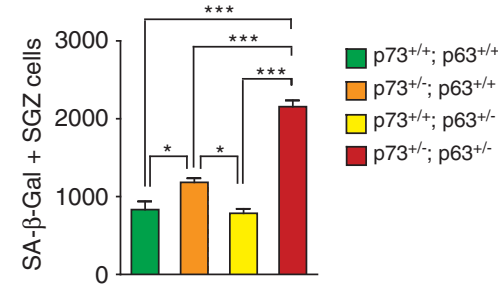

d

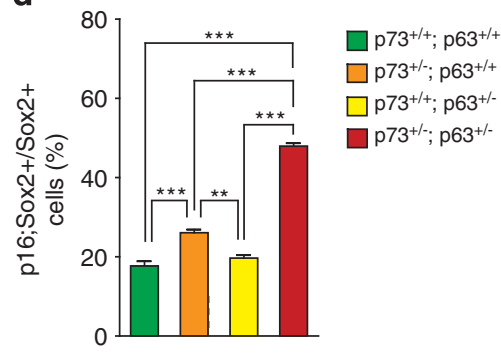

g

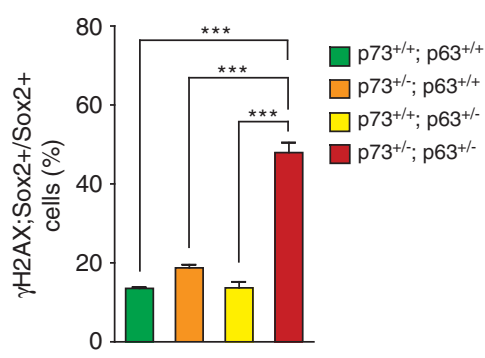

Figure 6 Adult $p 63^{+/-} ; p 73^{+/-}$dentate gyrus NPCs display increased senescence and DNA damage in vivo. (a and $\left.\mathbf{b}\right)$ Coronal sections through the hippocampus of 3-month-old wild-type $\left(\mathrm{p} 73^{+I+} ; \mathrm{p} 63^{+I+}\right), \mathrm{p} 73^{+I-} ; \mathrm{p} 63^{+1+}, \mathrm{p} 73^{+1+} ; \mathrm{p} 63^{+I-}$, and $\mathrm{p} 63^{+I-} ; \mathrm{p} 73^{+I-}$ mice were stained for senescence-associated $\beta$-galactosidase (SA- $\beta$-Gal; dark blue, arrows, a), counterstained with Hoechst (pseudocolored gold, a), and the total relative numbers of positive cells in the SGZ were quantified (b). ${ }^{\star} P<0.05,{ }^{* \star} P<0.001, n=3$ per genotype. Scale bar $=100 \mu \mathrm{m}$. (c) Confocal micrographs through the wild-type and double heterozygote dentate gyrus immunostained for Sox2 (green), p16 (red), and counterstained with Hoechst 33258 (blue in the merged images on the right). Arrows denote double-positive cells, and the white hatched lines indicate the borders between the DG and the SGZ. Scale bar $=18 \mu \mathrm{m}$. (d) Quantification of the proportion of Sox2-positive NPCs that were also positive for p16, as determined in 10 sections/mouse similar to those in $\mathbf{c}$. ${ }^{\star \star} P<0.01,{ }^{\star \star \star} P<0.001, n=3$ per genotype. (e) Quantification of the total relative numbers of SA- $\beta$-Gal-positive

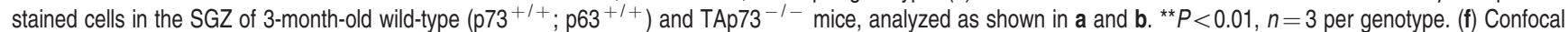
micrographs through the wild-type and double heterozygote dentate gyrus immunostained for Sox ( $g r e e n$ ), $\gamma \mathrm{H} 2 \mathrm{AX}$ (red), and counterstained with Hoechst 33258 (blue in the merged images on the right). Arrows denote double-positive cells, and the white hatched lines indicate the borders between the DG and the SGZ. Scale bar $=18 \mu \mathrm{m}$. ( $\mathbf{g}$ ) Quantification of the proportion of Sox2-positive NPCs that were also positive for $\gamma \mathrm{H} 2 \mathrm{AX}$, as determined in 10 sections/mouse similar to those in $\mathrm{f}$. ${ }^{\star \star \star} P<0.001, n=3$ per genotype

Sox2-negative postmitotic neurons, as previously reported. ${ }^{18}$ In contrast, the proportion of $\mathrm{p} 16^{\text {ink4a }}$-positive, Sox2-positive NPCs was increased to approximately $26 \%$ and $50 \%$, respectively, in the $\mathrm{p} 73^{+/-}$and $\mathrm{p} 63^{+I-} ; \mathrm{p} 73^{+/-}$dentate gyrus (Figure 6d).

The predominant p73 isoform in NPCs is TAp73. ${ }^{10,11} \mathrm{We}$ therefore asked whether this enhanced senescence was also seen in TAp73 $3^{-1-}$ mice by staining the dentate gyrus for SA- $\beta$-gal. This analysis showed that, although the dentate gyrus is truncated in TAp73 mice, ${ }^{10,11}$ the total number of SA- $\beta$-gal-positive cells per dentate gyrus was almost doubled (Figure 6e).

One cause of cellular senescence is DNA damage. We therefore asked whether the p73-dependent increase in NPC senescence might be due to enhanced DNA damage by immunostaining the dentate gyrus for Sox2 and the DNA damage marker phospho-histone $\mathrm{H} 2 \mathrm{~A}$, member $\mathrm{X}(\gamma \mathrm{H} 2 \mathrm{AX}$; Figure 6f). In wild-type, $\mathrm{p} 73^{+/-}$, and $\mathrm{p} 63^{+/-}$mice, about 15-20\% of Sox2-positive NPCs co-expressed $\gamma \mathrm{H} 2 \mathrm{AX}$,

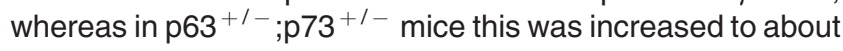
$50 \%$ (Figure 6g).

To further examine the relationship between DNA damage, apoptosis, and senescence in NPCs of these different genotypes, we cultured adult SVZ neurospheres, treated them with or without camptothecin for $5 \mathrm{~h}$, and then stained for SA- $\beta$-gal (Figure 7a). Under basal conditions, $5-9 \%$ of wild-type, $\mathrm{p} 63^{+/-}$, and $\mathrm{p} 73^{+/-}$neurosphere cells were SA$\beta$-gal-positive, and this number was doubled in $\mathrm{p} 63^{+/-}$;

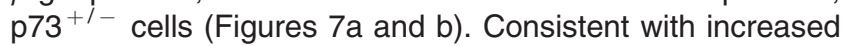
basal senescence, western blot analyses showed that p16 ${ }^{\text {ink4a }}$ levels were higher in $\mathrm{p} 73^{+/-}$and $\mathrm{p} 63^{+/-} ; \mathrm{p} 73^{+/-}$ neurospheres (Figure 7c). Following camptothecin treatment, 
a

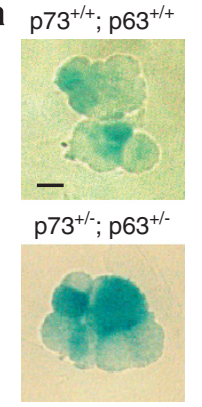

d

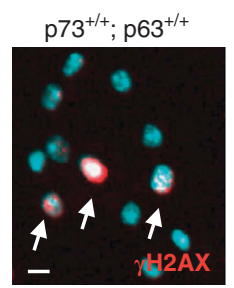

b

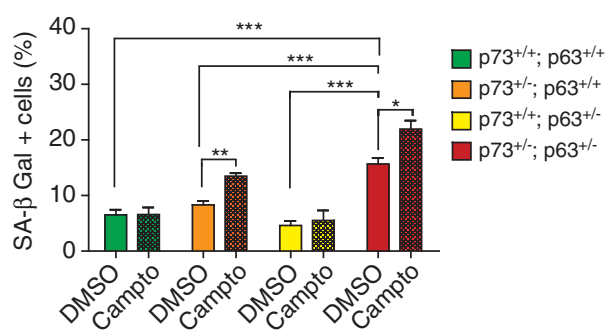

c

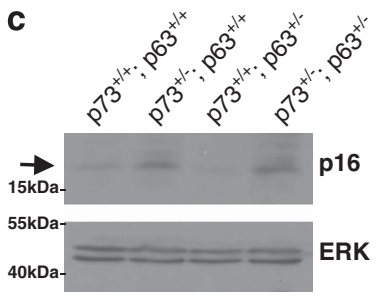

e

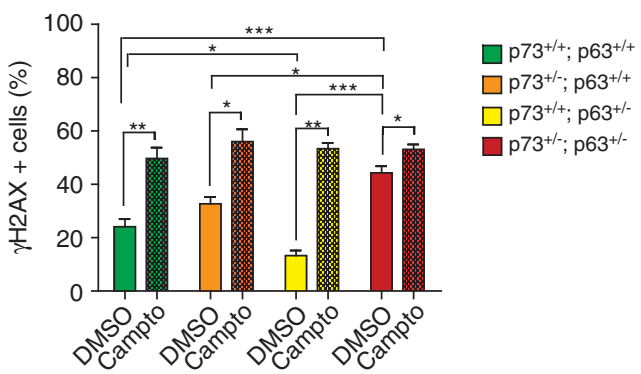

f Alkaline Comet Assay

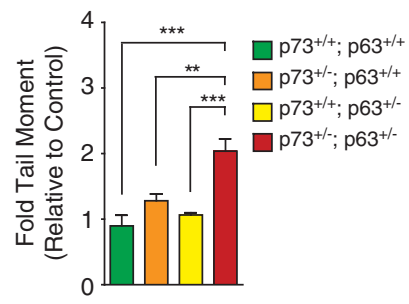

i

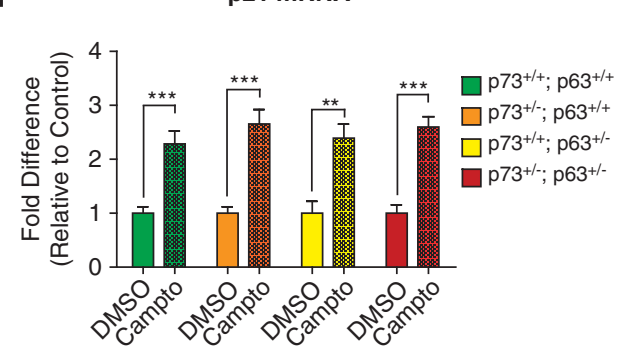

g P21 mRNA

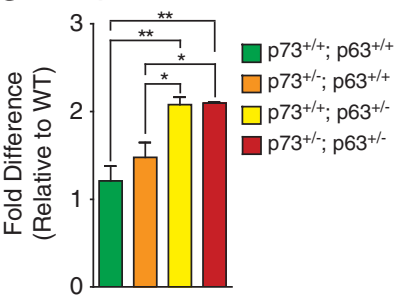

h PUMA MRNA

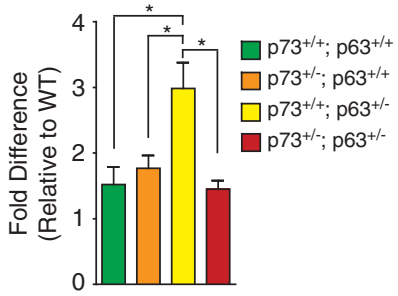

j

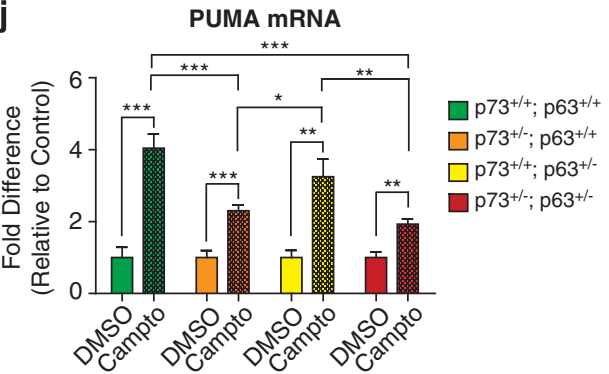

Figure $7 \mathrm{p} 63^{+1-} ; \mathrm{p} 73^{+1-}$ NPCs display increased senescence and DNA damage in culture. (a and $\left.\mathbf{b}\right)$ Primary neurospheres cultured for 6 days from the SVZ of 3-month-old wild-type $\left(\mathrm{p} 73^{+1+} ; \mathrm{p} 63^{+1+}\right), \mathrm{p} 73^{+1-} ; \mathrm{p} 63^{+1+}, \mathrm{p} 73^{+1+} ; \mathrm{p} 63^{+1-}$, and $\mathrm{p} 63^{+1-} ; \mathrm{p} 73^{+1-}$ mice were exposed to $10 \mu \mathrm{m}$ camptothecin (Campto) or vehicle (DMSO) for $5 \mathrm{~h}$, stained for SA- $\beta$-Gal (a) and the percentage of positive cells was determined (b). Three mice of each genotype were analyzed in triplicate wells, and at least 200 cells were counted per genotype per condition. ${ }^{\star} P<0.05,{ }^{\star \star} P<0.01,{ }^{* \star *} P<0.001$. Scale bar $=8 \mu \mathrm{m}$. (c) Western blot analysis for $p 16$ in total cell lysates from secondary neurospheres of all four genotypes under basal conditions. Total ERK is shown as a loading control. Arrow denotes the p16 band, and the numbers represent migration of MW markers. (d and e) Primary neurospheres cultured for 6 days from the SVZ of adult mice of all four genotypes were exposed to $10 \mu \mathrm{m}$ camptothecin (Campto) or vehicle (DMSO) for $5 \mathrm{~h}$, immunostained for $\gamma \mathrm{H} 2 \mathrm{AX}$ (red, $\mathrm{d}$ ), counterstained with Hoechst (blue, $\mathrm{d}$ ), and the proportion of $\gamma \mathrm{H} 2 \mathrm{AX}$-positive cell was determined (e). Arrows denote $\gamma \mathrm{H} 2 \mathrm{AX}$-positive cells. Three mice of each genotype were analyzed and at least 150 cells were counted per genotype per condition. ${ }^{*} P<0.05,{ }^{* *} P<0.01,{ }^{* * *} P<0.001$. Scale $\mathrm{bar}=15 \mu \mathrm{m}$. (f) Quantification of DNA integrity using comet assays. Primary neurospheres cultured for 6 days were dissociated to single cells, and following the comet assay, the average tail moment was calculated from over 50 cells of each genotype and expressed as a fold change relative to wild type. ${ }^{\star \star} P<0.01,{ }^{* \star *} P<0.001, n \geq 3$ individual mice per genotype. ( $\mathbf{g}$ and $\mathbf{h}$ ) Quantitative real-time PCR was performed on the dentate gyrus of 3-month-old mice from all four genotypes, using Taqman probes specific for either p21 ${ }^{\text {waf-1 }}(\mathbf{g})$ or PUMA (h) mRNA. Data are expressed relative to values for the wild-type dentate gyrus. ${ }^{*} P<0.05,{ }^{\star \star} P<0.01, n \geq 3$ per genotype. (i and j) Neurospheres from the SVZ of adult mice of all four genotypes that had been passaged one or two times were exposed to $10 \mu \mathrm{m}$ camptothecin (Campto) or vehicle (DMSO) for $5 \mathrm{~h}$, RNA was extracted, and quantitative real-time PCR was performed as in $\mathbf{g}$ and $\mathbf{h}$, using probes specific for either p21 ${ }^{\text {waf- }}$ (i) or PUMA (j) mRNA. Data are expressed relative to the DMSO controls for each genotype. ${ }^{*} P<0.05,{ }^{* *} P<0.01,{ }^{* *} P<0.001, n \geq 3$ per genotype

SA- $\beta$-gal-positive cells were unchanged in control and $p 63^{+/-}$ neurosphere cultures, but were significantly increased in $\mathrm{p} 73^{+/-}$and $\mathrm{p} 73^{+/-} ; \mathrm{p} 63^{+/-}$cultures (Figure $7 \mathrm{~b}$ ).
We also analyzed these cultures for DNA damage by immunostaining for $\gamma \mathrm{H} 2 \mathrm{AX}$ (Figure 7d). Under basal conditions, $15-30 \%$ of wild-type, $\mathrm{p} 73^{+/-}$and $\mathrm{p} 63^{+/-}$neurosphere 
cells expressed $\gamma \mathrm{H} 2 \mathrm{AX}$ and this was increased to approximately $50 \%$ in $\mathrm{p}^{+/-} ; \mathrm{p} 73^{+/-}$cultures (Figure $7 \mathrm{e}$ ). Following camptothecin treatment, $55-60 \%$ of cells of all genotypes were $\gamma \mathrm{H} 2 \mathrm{AX}$-positive, consistent with camptothecin's known genotoxic actions (Figure 7e). Analysis of DNA damage by the alkaline comet assay confirmed that under basal conditions $\mathrm{p} 63^{+/-} ; \mathrm{p} 73^{+/-}$neurosphere cells had accumulated significantly higher levels of DNA damage (Figure 7f). To find if this was due to chromosomal instability, we karyotyped adult SVZ neurospheres from mice of all genotypes (Supplementary Figure 2). Chromosomal karyotypes were apparently normal, arguing that p63;p73 haploinsufficiency does not cause changes to overall chromosomal integrity.

These data indicate that DNA damage causes apoptosis in wild-type and $\mathrm{p} 63^{+/}$neurosphere cells (shown in Figures $5 c-f)$, and senescence in $p 73^{+/-}$and $p 63^{+/-} ; p 73^{+/-}$cells (Figure 7b). One explanation for these differences is that p53 family target genes are differentially regulated. To test this idea, we used quantitative reverse transcriptase-PCR to evaluate mRNAs for the canonical p53 response gene p2 $1^{\text {waf-1 }}$ (CDKN1A), and the apoptotic effector PUMA in the dentate gyrus of different genotypes. This analysis showed that $\mathrm{p} 21^{\text {waf- } 1}$ mRNA was significantly elevated in $\mathrm{p} 63^{+/-}$and double heterozygote mice, consistent with aberrant activation of p53 in both genotypes (Figure $7 \mathrm{~g}$ ). In contrast, PUMA mRNA levels were elevated in the $p 63^{+/}$but not double heterozygote dentate gyrus (Figure 7h), suggesting that normal levels of p73 are necessary for PUMA but not p $21^{\text {waf- } 1}$ induction.

To further explore this differential gene regulation, we exposed SVZ neurospheres to camptothecin, and analyzed p21 $1^{\text {waf- } 1}$ and PUMA mRNAs. Camptothecin increased p21 $1^{\text {waf-1 }}$ mRNA levels approximately threefold in all groups (Figure 7i). In contrast, camptothecin increased PUMA mRNA about three- to fourfold in wild-type and $\mathrm{p} 63^{+/-}$neurospheres, but this response was significantly blunted in $\mathrm{p} 73^{+/-}$and $\mathrm{p} 73^{+/-} ; \mathrm{p} 63^{+/-}$neurospheres (Figure $7 \mathrm{j}$ ). These data are consistent with a model where genotoxic stress causes apoptosis of wild-type and $\mathrm{p} 63^{+/-}$NPCs, but when TAp73 levels are decreased in $\mathrm{p} 73^{+/-}$or $\mathrm{p} 63^{+/-} ; \mathrm{p} 73^{+/-}$NPCs, PUMA is not induced sufficiently to cause apoptosis, and cellular senescence ensues.

Concomitant deletion of p53 rescues the apoptosis and senescence phenotypes caused by haploinsufficiency for p63 and p73. We previously showed that the increased NPC death seen in $p 63^{+/}$mice was due to p53-dependent apoptosis. ${ }^{4}$ We therefore asked whether the hippocampal NPC deficits observed in $\mathrm{p} 63^{+/-} ; \mathrm{p} 73^{+/-}$NPCs were also due to $\mathrm{p} 53$ by crossing $\mathrm{p} 63^{+/-} ; \mathrm{p} 73^{+/-}$mice into a $\mathrm{p} 53^{-/-}$ background. Nissl staining showed that although the hippocampus was morphologically similar in $\mathrm{p} 63^{+/-} ; \mathrm{p} 73^{+/-}$mice with or without p53, the dentate gyrus blades were apparently thicker in the absence of p53 (Figure 8a). Consistent with this, immunostaining for Sox2 and doublecortin (Supplementary Figures $3 a$ and b) showed that genetic ablation of p53 completely rescued the decreased numbers of NPCs and newborn neurons in the $\mathrm{p} 63^{+/-} ; \mathrm{p} 73^{+/-}$SGZ (Figures $8 \mathrm{~b}$ and $\mathrm{c}$ ). Similar results were obtained when proliferating NPCs were quantified by analyzing
BrdU-positive SGZ cells 1 day post-BrdU administration (Figure 8d; Supplementary Figure 3c).

These data indicate that loss of p53 rescues the NPC deficits in double heterozygote mice. To ask if this was because it rescued the cell senescence phenotype, we quantified SA- $\beta$-gal- and p16 ink4a -positive cells in the SGZ. The number of SA- $\beta$-gal-positive cells was rescued to wildtype levels in the $\mathrm{p} 63^{+/-} ; \mathrm{p} 73^{+/-} ; \mathrm{p} 53^{-/-}$SGZ (Figures $8 \mathrm{e}$ and $\mathrm{f}$ ) as was the proportion of Sox2-positive, p16 ${ }^{\text {ink4a }}$ positive precursors (Figure $8 \mathrm{~g}$ ). To ask whether p53 deletion also rescued the DNA damage, we immunostained sections for $\gamma \mathrm{H} 2 \mathrm{AX}$. 50-60\% of Sox2-positive SGZ NPCs were $\gamma \mathrm{H} 2 \mathrm{AX}$ positive in $\mathrm{p} 63^{+/-} ; \mathrm{p} 73^{+/-}$mice regardless of whether they were $\mathrm{p} 53^{+/+}$or $\mathrm{p} 53^{-1-}$ (Figure $8 \mathrm{~h}$ ). Thus, genetic ablation of p53 rescues NPC senescence, but not DNA damage.

One way p53 is thought to induce senescence is via induction of p2 $1^{\text {waf- } 1}$. As p $21^{\text {waf- } 1}$ mRNA was elevated in the dentate gyrus of double heterozygotes (Figure 7g), we asked whether p53 deletion rescued this increase. Quantitative reverse transcriptase-PCR demonstrated that this was indeed the case, with $\mathrm{p} 21^{\text {waf- }} 1 \mathrm{mRNA}$ levels reduced to wild-type levels in the $\mathrm{p} 63^{+/-} ; \mathrm{p} 73^{+/-} ; \mathrm{p} 53^{-/-}$dentate gyrus (Figure 8i). In contrast, PUMA mRNA levels, which were already reduced to wild-type levels in the double heterozygote dentate gyrus (Figure 7h), were unaffected by loss of p53 (Figure 8j).

\section{Discussion}

In the adult mammalian brain, newly-born neurons contribute to key aspects of olfaction- and hippocampus-dependent learning and memory. The precursor cells generating these neurons are regulated by a number of extrinsic and intrinsic cues that signal self-renewal, proliferation, survival, and differentiation, thereby precisely determining the balance between NPC number and neurogenesis. These cues act by modulating the activity and expression of signaling proteins and genes, among them the p53 family. We and others have previously reported that $\triangle \mathrm{Np63}$ regulates NPC survival by inhibiting p53-induced apoptosis, ${ }^{4}$ while TAp73 is required for adult NPC self-renewal and maintenance. ${ }^{10,12-14}$ Here, we show that $\mathrm{p} 63$ and $\mathrm{p} 73$ interact functionally to regulate adult NPCs and neurogenesis, but that they do so via different underlying mechanisms, with $\Delta$ Np63 antagonizing p53's proapoptotic actions to promote cell survival, and TAp73 collaborating with p53 to determine apoptosis versus senescence. Thus, the p53 family acts together in adult NPCs to set the delicate balance between survival, cell death, and senescence.

Our most unexpected finding was that p73 heterozygosity converted a p53-dependent apoptotic response in $\mathrm{p} 3^{+/-}$ NPCs into a p53-dependent senescence response. How could this happen? The p53 family has previously been implicated in the regulation of apoptosis and senescence in at least some stem cell populations. For example, constitutive or elevated p53 activation causes depletion of adult stem cell populations by increased PUMA-dependent apoptosis, ${ }^{4,19}$ whereas decreased p63 or p73 levels can cause premature senescence in both somatic cells and stem cells. ${ }^{20-22}$ Although we still do not understand how this family decides 
a
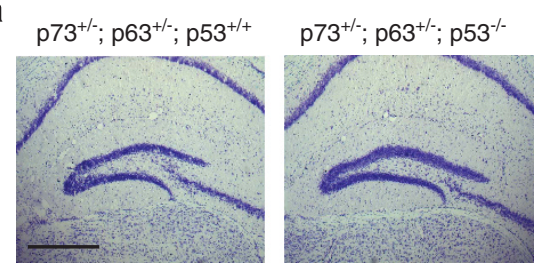

C

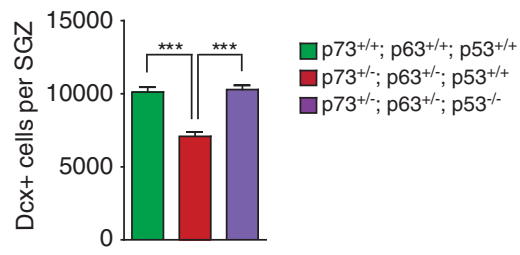

e

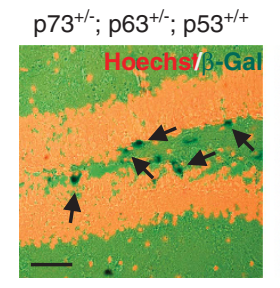

$\mathrm{p} 73^{+/-} ; \mathrm{p} 63^{+/-} ; \mathrm{p} 53^{-/-}$

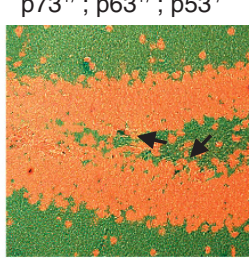

g

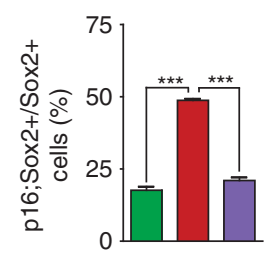

i

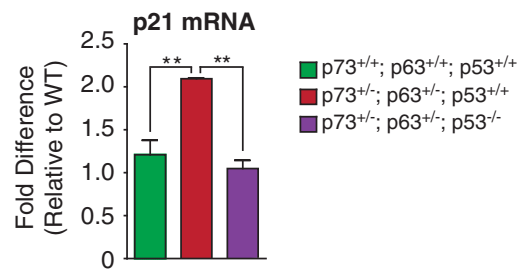

b

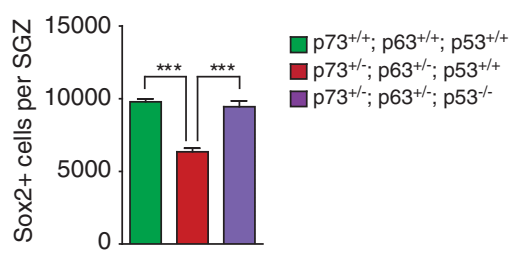

d

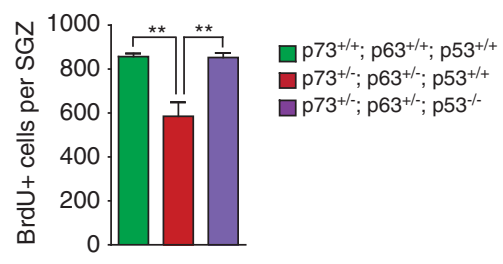

f

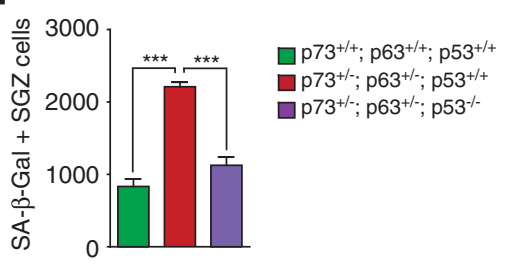

h

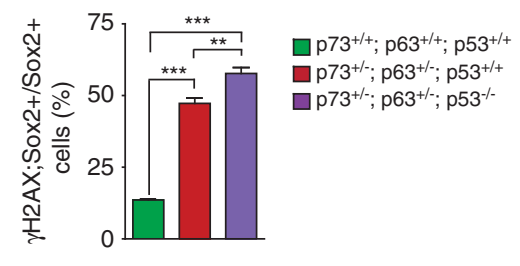

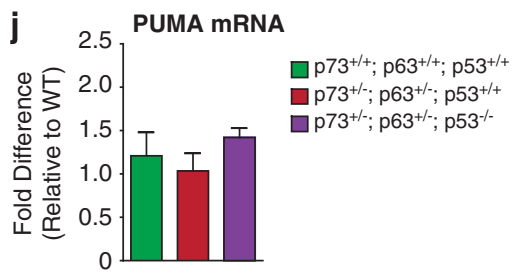

Figure 8 Coincident p53 ablation rescues the increased senescence in adult p63 $3^{+1-} ; \mathrm{p} 73^{+/-}$dentate gyrus NPCs in vivo. The dentate gyrus of 3-month-old mice of three different genotypes, $\mathrm{p} 73^{+1+} ; \mathrm{p} 63^{+/+} ; \mathrm{p} 53^{+1+}, \mathrm{p} 73^{+/-} ; \mathrm{p} 63^{+/-} ; \mathrm{p} 53^{+1+}$, and $\mathrm{p} 73^{+/-} ; \mathrm{p} 63^{+/-} ; \mathrm{p} 53^{-1-}$ were analyzed for neurogenesis and senescence phenotypes. (a) Micrographs of representative Nissl-stained coronal hippocampal sections from $\mathrm{p} 73^{+l-} ; \mathrm{p} 63^{+l-} ; \mathrm{p} 53^{+1+}$, and $\mathrm{p} 73^{+I_{-}} ; \mathrm{p} 63^{+l-} ; \mathrm{p} 53^{-l-}$ mice. Scale bar $=500 \mu \mathrm{m}$. (b and $\mathbf{c})$ Quantification of the total relative number of dentate gyrus SGZ cells expressing either Sox2 (b) or doublecortin (Dcx; $\mathbf{c}$ ), as determined from sections similar to those in Supplementary Figures $3 a$ and $b .{ }^{* \star \star} P<0.001, n \geq 3$ per genotype. (d) Quantification of the total relative number of BrdU-positive proliferating precursors in the SGZ $24 \mathrm{~h}$ following BrdU injection, as determined from sections similar to those in Supplementary Figure $3 c$. ${ }^{* *} P<0.01, n \geq 3$ per genotype. (e) Micrographs of coronal sections through the dentate gyrus stained for senescence-associated $\beta$-galactosidase (SA- $\beta$-Gal; dark blue, arrows, a), counterstained with Hoechst (pseudocolored gold). Scale bar $=50 \mu \mathrm{m}$. (f) Quantification of the total relative number of SA- $\beta$-Gal positive cells in the SGZ, as determined from sections similar to those in $\mathrm{e}$. ${ }^{* *} P<0.01$, ${ }^{* \star *} P<0.001, n \geq 3$ per genotype. ( $\mathbf{g}$ and $\mathbf{h}$ ) Quantification of the proportion of Sox2-positive NPCs in the SGZ that were also positive for p16 (g) or $\gamma \mathrm{H} 2 \mathrm{AX}(\mathbf{h})$, as determined from sections similar to those in Figures $6 c$ and $f .{ }^{* *} P<0.01,{ }^{* *} P<0.001, n \geq 3$ per genotype. (i and j) Quantitative real-time PCR was performed on the dentate gyrus isolated from $\mathrm{p} 73^{+/-} ; \mathrm{p} 63^{+I_{-}} ; \mathrm{p} 53^{+I_{+}}$, and $\mathrm{p} 73^{+/-} ; \mathrm{p} 63^{+I^{-}} ; \mathrm{p} 53^{-I-}$ mice, using Taqman probes specific for either p21 ${ }^{\text {waf-1 }}$ (i) or PUMA (j) mRNAs. Results for wild-type mice analyzed in Figures $7 \mathrm{~g}$ and $\mathrm{h}$ are shown for comparison. ${ }^{*} P<0.05,{ }^{* *} P<0.01, n \geq 3$ per genotype

whether a stem cell should apoptose or senesce, our data are consistent with a model where the balance of different family members determines this response. In this regard, we know that the adult NPCs preferentially express p53, $\Delta \mathrm{Np} 63$, and TAp73, ${ }^{4,8-14}$ and our previous work indicates that $\Delta N p 63$ functions to antagonize a p53-PUMA-dependent apoptotic pathway in NPCs, thereby ensuring cell survival. ${ }^{4}$ Moreover, our new data demonstrate increased levels of both PUMA and p $21^{\text {waf- } 1}$ mRNAs in the $p 63^{+/-}$dentate gyrus supporting the idea that the coincident increased NPC apoptosis is due to a p53-dependent increase in PUMA.

How then does haploinsufficiency for p73 convert this response to senescence rather than apoptosis? One major clue comes from our data showing (i) that in the 
$\mathrm{p} 73^{+/-} ; \mathrm{p} 63^{+/-}$dentate gyrus, $\mathrm{p} 21^{\text {waf-1 }}$ but not PUMA mRNA levels were aberrantly increased, (ii) that this increase in p21 waf-1 mRNA in the dentate gyrus required p53, as did the increased senescence, and (iii) that the camptothecin-induced increase in PUMA, but not $\mathrm{p} 21^{\text {waf- } 1}$ mRNA was blunted when $p 73$ was haploinsufficient. On the basis of these findings, we propose that DNA damage activates p53 and TAp73 to increase transcription of $\mathrm{p} 21^{\text {waf- } 1}$ and PUMA mRNAs, and ultimately cause PUMA-dependent NPC apoptosis. This damage response is normally antagonized by $\Delta N p 63$, but when p63 is haploinsufficient, $\mathrm{p} 21^{\text {waf- } 1}$ and PUMA transcription are abnormally increased under basal conditions, and PUMAdriven apoptosis is the dominant response. However, when TAp73 levels are coincidently decreased, PUMA transcription is blunted, and cells do not apoptose. Instead, as (i) levels of p2 $1^{\text {waf- }} 1$ transcription are still high, and (ii) p53 has been shown to cause cell senescence via transcription of high levels of p21waf-1 ${ }^{23}$ then cell senescence is the ultimate outcome. In this model, p53-dependent senescence is a 'fall-back' response that only occurs when cells are damaged and PUMA (and potentially other p53-dependent apoptotic genes) is not induced.

One final phenotype we document here is a large increase in the proportion of NPCs with DNA damage under basal conditions in the $\mathrm{p} 73^{+/-} ; \mathrm{p} 63^{+/-}$dentate gyrus. This phenotype is perhaps not surprising as we and other have shown that TAp73 and TAp63 are essential for maintaining genomic stability. ${ }^{11,22,24,25}$ However, what is surprising is the finding that genetic ablation of $p 53$ can completely rescue the

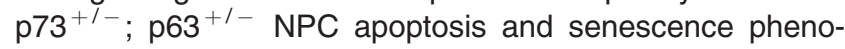
types even as it further increases the proportion of cells with DNA damage. As unrepaired DNA damage is thought to ultimately cause tumorigenesis and/or premature aging, it will be interesting to determine the long-term consequences of these genetic perturbations.

\section{Materials and Methods}

Animals. This study was approved by the Hospital for Sick Children Animal Care Committee, in accordance with Canadian Council on Animal Care guidelines. $\mathrm{p} 63^{+1-}$ mice ${ }^{15}$ were maintained on a C57BL/6 background, and $\mathrm{p} 73^{+1-}$ mice ${ }^{16}$ were maintained on a C129SvJae background as described previously. ${ }^{21,26,27}$ $\mathrm{p} 63^{+1-}$ and $\mathrm{p} 73^{+1-}$ mice were crossed to obtain $\mathrm{p} 63^{+1-} ; \mathrm{p} 73^{+/-}$mice and maintained on a mixed C57BL/6;C129SvJae background through double heterozygous wild-type breeder pairs. $\mathrm{p} 53^{-1-}$ mice ${ }^{28}$ were obtained from Jackson Laboratory, and crossed to $\mathrm{p} 63^{+I-} ; \mathrm{p} 73^{+I-}$ mice to generate triplecrossed $\mathrm{p} 63^{+1-} ; \mathrm{p} 73^{+1-} ; \mathrm{p} 53^{-1-}$ mice and maintained on a mixed C57BL $6 ; C 129$ SvJae background. Triple crossed mice were obtained through triple heterozygous matings. Three-month-old mice were used for all analyses, except for the adult-born neuron experiments, where mice were injected with BrdU at two months, and analyzed one month later at 3 months. TAp73 mice ${ }^{11}$ were maintained on a pure C57BL/6 background as previously described. ${ }^{10}$ Mice had access to food and water ad libitum in a 12-h light-dark cycle room.

Neuroanatomy and immunostaining of sections. For histology, mice were killed using an overdose of sodium pentobarbital, and subsequently transcardially perfused with PBS followed by $4 \%$ paraformaldehyde. Brains were then post-fixed overnight in $4 \%$ paraformaldehyde, dehydrated in 30\% sucrose, cryoprotected, and coronally sectioned at $20 \mu \mathrm{m}$ using a Leica CM 1850 cryostat (Leica Biosystems, Concord, ON, Canada). Immunostaining of brain sections was performed as described previously. ${ }^{4}$ Briefly, sections were washed with TBS, permeabilized with $0.4 \%$ Triton X-100 in TBS, and blocked with $5 \%$ BSA, $0.4 \%$ Triton X-100 in TBS. Slides were then incubated overnight at $4{ }^{\circ} \mathrm{C}$ with primary antibody diluted in blocking solution. Slides were washed with TBS, incubated with secondary antibody in blocking solution for $1 \mathrm{~h}$ at room temperature, and mounted with Permount solution (Thermo Scientific, Walthman, MA, USA). For $\gamma \mathrm{H} 2 \mathrm{AX}$ staining, antigen retrieval was performed by boiling slides in citrate buffer at $95^{\circ} \mathrm{C}$ for $20 \mathrm{~min}$. Slides were allowed to cool to room temperature, followed by permeabilization and blocking as above. SA- $\beta$-Gal staining was performed using a kit (Cell Signaling, Danvers, MA, USA), following the manufacturer's instructions. Briefly, sections were washed with PBS, and incubated overnight in staining solution (pH 6.0).

Quantification of sections. For quantification of stained sections, images were captured using either Axiovision software (Zeiss, Oberkochen, Germany) on a Zeiss Axioplan 2 microscope with a Hamamatsu (Bridgewater, NJ, USA) OrcaR2 CCD camera or with Volocity software (Perkin-Elmer, Waltham, MA, USA) on an Olympus (Center Valley, PA, USA) IX81F-3 confocal microscope with a Hamamatsu EM-CCD camera. Dentate gyrus thickness was quantified as previously described. ${ }^{4}$ Briefly, the thickness of both the upper and lower blades was measured at three different points per blade in 10 sections per animal that spanned the entire rostrocaudal extent of the hippocampus. Average granule cell density in the olfactory bulb was quantified by counting the number of neurons within one random field in each of 10 sections per animal. To obtain total relative numbers of stained cells within the dentate gyrus, the entire hippocampus was sectioned, and all positive cells were counted in 10 sections, sampled every tenth section, after staining. The number of positive cells was then multiplied by 10 (to compensate for sampling frequency) to obtain the total relative number of positive cells in the dentate gyrus. To obtain the proportion of double-labeled cells, all single- and double-labeled cells were counted in 10 sections spanning the entirety of the hippocampus. The SGZ was defined as the two cell layers beneath the granular cell layer of the hippocampus. Analyses of the lateral ventricle were performed in a similar manner to those described above for the hippocampus.

BrdU labeling. To quantify proliferating precursors in the SGZ and SVZ, mice were injected intraperitoneally with a single dose of $100 \mathrm{mg} / \mathrm{kg} \mathrm{BrdU}$ (SigmaAldrich, St. Louis, MO, USA). Animals were then killed $24 \mathrm{~h}$ later and transcardially perfused as described above. The brains were coronally sectioned, incubated in $1 \mathrm{~N} \mathrm{HCl}$ for $30 \mathrm{~min}$ at $60^{\circ} \mathrm{C}$, rinsed with TBS, incubated with anti-BrdU antibody at $4{ }^{\circ} \mathrm{C}$ overnight, and detected using an anti-rat secondary antibody. The total relative number of BrdU-labeled cells was determined as described above for immunostained sections. To quantify the number of adult-born neurons, 2-monthold mice were injected intraperitoneally with $100 \mathrm{mg} / \mathrm{kg} \mathrm{BrdU}$ every $2 \mathrm{~h}$ for a total of $8 \mathrm{~h}$ (five injections) and killed 30 days later at 3 months of age. The hippocampus was then sectioned, immunostained for BrdU, and the total relative number of BrdU-positive cells in the dentate gyrus was determined as described above. For olfactory neurogenesis, olfactory bulbs were sectioned at $18 \mu \mathrm{m}$ and 10 sections, sampled every 10th section, were immunostained for BrdU alone, as described above. In some experiments, after immunostaining for BrdU, sections were then incubated in primary antibodies for NeuN, calretinin, or tyrosine hydroxylase, followed by washes and secondary antibodies, as described above for the standard immunostaining protocol. All positive or double-positive cells were counted, and numbers were then multiplied by 10 (to account for sampling frequency) to obtain the total relative number of positive cells per olfactory bulb.

TUNEL labeling. For TUNEL labeling of Sox2-positive NPCs, sections were washed, permeabilized and blocked (as above), and incubated overnight with antiSox2 antibody. Sections were then washed and incubated for $1 \mathrm{~h}$ at room temperature with secondary antibody. After washes, TUNEL labeling was performed using the ApopTag Red In Situ Apoptosis Detection Kit (Chemicon, EMD Millipore, Billerica, MA, USA) following the manufacturer's protocol. The number of Sox2-positive cells that were and were not positive for TUNEL was determined in 10 sections/mouse.

Antibodies. The following primary antibodies and dilutions were used: goat anti-Sox2 (Y-17, 1:500, Santa Cruz Biotechnology, Santa Cruz, CA, USA), goat anti-doublecortin (C-18, 1:250, Santa Cruz Biotechnology), rat anti-BrdU (OBT0030, 1:200, ABD Serotec, Raliegh, NC, USA), AlexaFluor 488-conjugated mouse anti-NeuN (MAB377X, 1:100, EMD Millipore), mouse anti-Ki67 (556003, $1: 200$, BD Pharmingen, San Diego, CA, USA), rabbit anti-cleaved caspase-3 (AB3623, 1:250, EMD Millipore), mouse anti-p16 (F-12, 1:1000, Santa Cruz Biotechnology), mouse anti- $\gamma \mathrm{H} 2 \mathrm{AX}$ (05-636, 1:250, EMD Millipore), rabbit anticalretinin (ab702, 1:500, Abcam, Cambridge, MA, USA), and mouse anti-tyrosine 
hydroxylase (MAB318, 1:500, EMD Millipore). Secondary antibodies were AlexaFluor 488-conjugated donkey anti-goat, anti-rat, and anti-mouse $\operatorname{lgG}$ (1: 1000, Life Technologies, Grand Island, NY, USA), AlexaFluor 555-conjugated donkey anti-goat, anti-mouse, and anti-rabbit IgG (1:1000, Life Technologies).

Neurosphere cultures. For adult SVZ cultures, the subependyma of the lateral ventricles was dissected out as previously described. ${ }^{10}$ Cell density and viability were determined using trypan blue exclusion and a hemocytometer. Freshly isolated cells were then plated at a density of 10 cells $/ \mu$ in six-well $(2 \mathrm{ml}$ per well) ultra-low attachment plates (Corning, Corning, NY, USA) in serum-free medium containing $20 \mathrm{ng} / \mathrm{ml}$ EGF (Sigma-Aldrich), $10 \mathrm{ng} / \mathrm{ml} \mathrm{FGF2} \mathrm{(Sigma-Aldrich),}$ and $2 \mu \mathrm{g} / \mathrm{ml}$ heparin (Sigma-Aldrich). Primary neurospheres were counted on day 6 after dissection, with only spheres composed of over 10 cells being counted. Sphere diameter was quantified using Northern Eclipse software (Empix, Mississauga, ON, Canada), by drawing a line through the length of each sphere at 6 days of culture. To assess self-renewal, neurospheres were mechanically dissociated, passed through a $40-\mu \mathrm{m}$ cell strainer, plated at a density of 4 cells $/ \mu \mathrm{l}$ and counted 4 days later. ZVAD-fmk (Calbiochem, EMD Millipore) was added to some cultures at a final concentration of $50 \mu \mathrm{m}, 1$ day after dissection. Sphere number was then assessed 5 days later (on day 6). Camptothecin (Calbiochem) was added to neurosphere cultures for $5 \mathrm{~h}$ at a final concentration of $10 \mu \mathrm{m}$. DMSO was used as a vehicle control for all drug treatment experiments. For immunocytochemistry, neurospheres were attached to uncoated slides using a Shandon Cytospin 4 (Thermo Scientific) and stained using a protocol similar to brain sections. For SA- $\beta$-Gal staining, primary passage neurospheres were dissociated and plated on four-well chamber slides coated with $2 \%$ laminin (BD Biosciences, Mississauga, ON, Canada) and 1\% poly-D-lysine (Sigma-Aldrich). Cells were then left in a humidified incubator overnight to allow attachment. The following day, cells were treated with either camptothecin or DMSO for $5 \mathrm{~h}$, and SA- $\beta$-Gal was detected using a kit (Cell Signaling). Briefly, cells were washed twice with PBS, fixed with $0.2 \%$ glutaraldehyde, $2 \%$ formaldehyde in PBS, washed again, and incubated overnight in staining solution $\left(\mathrm{pH} 6.0\right.$ ) in a dry incubator (no $\mathrm{CO}_{2}$ ). Nuclei were counterstained with Hoechst 33342, and counted using an Axioskop (Zeiss) Model 451485 microscope. Pictures were taken using a QImaging (Surrey, BC, Canada) QICam 10 bit camera with Northern Eclipse software.

Western blots. Secondary neurospheres were grown as described above and collected 6 days after passage. Samples were lysed in Radioimmunoprecipitation assay buffer (RIPA) supplemented with $2 \mu \mathrm{g} / \mathrm{ml}$ Aprotinin, $10 \mu \mathrm{g} / \mathrm{ml}$ Leupeptin, $1 \mathrm{~mm}$ PMSF, $10 \mathrm{~mm}$ Sodium Fluoride, and $1 \mathrm{~mm}$ Sodium Orthovanadate. Equal amounts of protein $(20 \mu \mathrm{g})$ per sample were run on a $15 \%$ SDS-PAGE gel, transferred to a $0.2-\mu \mathrm{m}$ nitrocellulose membrane, blocked for $30 \mathrm{~min}$ with $5 \% \mathrm{BSA}$, $0.1 \%$ Tween-20 in TBS, and incubated overnight at $4{ }^{\circ} \mathrm{C}$ with primary antibody in blocking buffer. After several washes with $0.1 \%$ Tween-20 in TBS, membranes were incubated with either goat anti-mouse $(1: 5000)$ or goat anti-rabbit $(1: 10000)$ secondary antibody at room temperature for $1 \mathrm{~h}$. Detection was performed using ECL chemiluminescence reagent (GE Healthcare, Buckinghamshire, UK). Primary antibodies were mouse anti-p16 (F-12, 1:1000, Santa Cruz Biotechnology) and rabbit anti-ERK1 (K-23, 1: 10 000, Santa Cruz Biotechnology).

Alkaline Comet Assay. The comet assay was performed using the CometAssay Kit (Trevigen, Gaithersburg, MD, USA) following the manufacturer's protocol. Briefly, dissociated neurosphere cells were re-suspended in low-melting point agarose and placed onto CometSlides, allowed to solidify at $4{ }^{\circ} \mathrm{C}$, then incubated overnight in lysis solution at $4{ }^{\circ} \mathrm{C}$. Slides were then placed in alkaline unwinding solution $(\mathrm{pH} \mathrm{13})$ for $1 \mathrm{~h}$, and electrophoresed at $1 \mathrm{~V} / \mathrm{cm}$ for $45 \mathrm{~min}$ at $4{ }^{\circ} \mathrm{C}$. Nuclei were counterstained with SYBR Gold (Life Technologies), and images were quantified using CASP software version 1.2.3 (CASPLab, University of Wroclaw, Wroclaw, Poland)

Quantitative PCR. Quantitative PCR was performed as previously described. ${ }^{4}$ Briefly, RNA was extracted using Trizol Reagent (Life Technologies), treated with DNase I (Fermentas, Thermo Scientific, Waltham, MA, USA), and cDNA was synthesized from $1 \mu \mathrm{g}$ of RNA using RevertAid $\mathrm{H}$ Minus M-MulV Reverse Transcriptase (Fermentas). Quantitative PCR was then performed using Taqman gene expression Mastermix (Life Technologies) and Taqman probes designed against either Bbc3 (PUMA, Mm00519268_m1), p21
(Mm04205640_g1), or GAPDH (Mm99999915_g1). GAPDH mRNA was used as an endogenous control for all reactions, and all reactions were performed in at least duplicate. Quantitative PCR was run using ABI Prism 7900HT Real-Time PCR system (Life Technologies), and analyzed using SDS version 2.4 software (Life Technologies).

Reverse transcriptase (RT)-PCR. RT-PCR was performed as previously described. ${ }^{4}$ RNA was extracted and cDNA was synthesized as above, and PCR was performed using Phusion High-Fidelity DNA Polymerase (Thermo Scientific). The primers used for RT-PCR were as follows: p53 forward, 5'-AACCGCC GACCTATCCTTACCATC-3'; p53 reverse, 5'-AGGCCCCACTTTCTTGACC ATTGT-3'; p63 forward, 5'-GACCGGAAGGCAGATGAAGACAG-3'; p63 reverse, 5'-TGTTTCTGAAGTAGGTGCTGGTGC-3'; p73 forward, 5'-GCCATGCCTGTCT ACAAGAA-3'; p73 reverse, 5'-TGTTGCCTTCTACACGGATG-3'; GAPDH forward, 5'-ACGGCAAGTTCAATGGCACAGTCA-3'; GAPDH reverse, 5'-GCTTTCCAG AGGGGCCATCCACAG- $3^{\prime}$. All products were single bands of predicted molecular weight.

Cytogenetics. Karyotyping was performing by the Centre for Applied Genomics at the Hospital for Sick Children. Cultured neural precursors were treated with $0.05 \mu \mathrm{g} / \mathrm{ml}$ Colcemid, dispersed with $75 \mathrm{mM} \mathrm{KCl}$, fixed in $75 \%$ methanol/25\% acetic acid, and stained with 10\% Leishman/8\% Giemsa (pH 6.8). Images were acquired using an Olympus BX61 microscope and analyzed using BandView Software (Applied Spectral Imaging, Carlsbad, CA, USA).

Statistics. Statistics were performed using the one-way ANOVA with Tukey's post-hoc test to test for significance unless otherwise stated. For the drug treatment experiments, significance between the two treatment groups was determined using the Student's Paired t-test, and significance across genotypes was determined with a two-way ANOVA with Tukey's post-hoc test. All analyses were performed using Prism 5 (GraphPad, La Jolla, CA, USA). In all cases, error bars indicate standard error of the mean.

\section{Conflict of Interest}

The authors declare no conflict of interest.

Acknowledgements. This work was funded by CIHR grants MOP-38021 and MOP-14446 to FDM and DRK. GIC was funded by fellowships from the Heart and Stroke Foundation of Canada and Becas Chile, FDM and DRK hold Canada Research Chairs, and FDM is an HHMI Senior International Research Scholar. We thank Frank McKeon (Harvard) for the generous gift of p73 knockout mice, and Alea Mills (Cold Spring Harbour Laboratories) for the gift of p63 knockout mice. We thank Benigno Aquino and Vania Ariosa for technical assistance.

1. Deng W, Aimone JB, Gage FH. New neurons and new memories: how does adult hippocampal neurogenesis affect learning and memory? Nat Rev Neurosci 2010; 11: 339-350.

2. Ming GL, Song $\mathrm{H}$. Adult neurogenesis in the mammalian brain: significant answers and significant questions. Neuron 2011; 70: 687-702.

3. Flores ER, Tsai KY, Crowley D, Sengupta S, Yang A, McKeon F et al. p63 and p73 are required for p53-dependent apoptosis in response to DNA damage. Nature 2002; 416: 560-564.

4. Cancino GI, Yiu AP, Fatt MP, Dugani CB, Flores ER, Josselyn SA et al. p63 Regulates adult neural precursor and newly born neuron survival to control hippocampal-dependent behavior. J Neurosci 2013; 33: 12569-12585.

5. Li Y, Prives $C$. Are interactions with $p 63$ and $p 73$ involved in mutant $p 53$ gain of oncogenic function? Oncogene 2007; 26: 2220-2225.

6. Rocco JW, Leong CO, Kuperwasser N, DeYoung MP, Ellisen LW. p63 mediates survival in squamous cell carcinoma by suppression of p73-dependent apoptosis. Cancer Cell 2006; 9: $45-56$.

7. Dötsch V, Bernassola F, Coutandin D, Candi E, Melino G. p63 and p73, the ancestors of p53. Cold Spring Harb Perspect Biol 2010; 2: a004887.

8. Meletis K, Wirta V, Hede SM, Nistér M, Lundeberg J, Frisen J. p53 supresses the selfrenewal of adult neural stem cells. Development 2006; 133: 363-369.

9. Gil-Perotin S, Marin-Husstege M, Li J, Soriano-Navarro M, Zindy F, Roussel MF et al. Loss of p53 induces changes in the behavior of subventricular zone cells: implication for the genesis of glial tumors. J Neurosci 2006; 26: 1107-1116. 
10. Fujitani M, Cancino GI, Dugani CB, Weaver IC, Gauthier-Fisher A, Paquin A et al. TAp73 acts via the bHLH Hey2 to promote long-term maintenance of neural precursors. Curr Biol 2010; 20: 2058-2065.

11. Tomasini R, Tsuchihara K, Wilhelm M, Fujitani M, Rufini A, Cheung CC et al. TAp73 knockout shows genomic instability with infertility and tumor suppressor functions. Genes Dev 2008; 22: 2677-2691.

12. Agostini $M$, Tucci $P$, Chen $H$, Knight RA, Bano $D$, Nicotera $P$ et al. p73 regulates maintenance of neural stem cell. Biochem Biophys Res Commun 2010; 403: 13-17.

13. Talos F, Abraham A, Vaseva AV, Holembowski L, Tsirka SE, Scheel A et al. p73 is an essential regulator of neural stem cell maintenance in embryonal and adult CNS neurogenesis. Cell Death Diff 2010; 17: 1816-1829.

14. Gonzalez-Cano L, Herreros-Villanueva M, Fernandez-Alonso R, Ayuso-Sacido A, Meyer G, Garcia-Verdugo JM et al. p73 deficiency results in impaired self renewal and premature neuronal differentiation of mouse neural progenitors independently of p53. Cell Death Dis 2010; 1: e109.

15. Mills AA, Zheng B, Wang XJ, Vogel H, Roop DR, Bradley A. p63 is a p53 homologue required for limb and epidermal morphogenesis. Nature 1999; 398: 708-713.

16. Yang A, Walker N, Bronson R, Kaghad M, Oosterwegel M, Bonnin J et al. p73-deficient mice have neurological, pheromonal and inflammatory defects but lack spontaneous tumours. Nature 2000; 404: 99-103.

17. Imayoshi I, Sakamoto M, Ohtsuka T, Takao K, Miyakawa T, Yamaguchi M et al. Roles of continuous neurogenesis in the structural and functional integrity of the adult forebrain. Nat Neurosci 2008; 11: 1153-1161.

18. van Lookeren Campagne M, Gill R. Tumor-suppressor $p 53$ is expressed in proliferating and newly formed neurons of the embryonic and postnatal rat brain: comparison with expression of the cell cycle regulators p21Waf1/Cip1, p27Kip1, p57Kip2, p16Ink4a, Cyclin G1, and the proto-oncogene Bax. J Comp Neurol 1998; 397: 181-198.

19. Liu D, Ou L, Clemenson Jr GD, Chao C, Lutske ME, Zambetti GP et al. Puma is required for p53-induced depletion of adult stem cells. Nat Cell Biol 2010; 12: 993-998.

20. Keyes WM, Wu Y, Vogel H, Guo X, Lowe SW, Mills AA. p63 deficiency activates a program of cellular senescence and leads to accelerated aging. Genes Dev 2005; 19 : 1986-1999.

21. Wetzel MK, Naska S, Laliberté CL, Rymar VV, Fujitani M, Biernaskie JA et al. p73 regulates neurodegeneration and phospho-tau accumulation during aging and Alzheimer's disease. Neuron 2008; 59: 708-721.

22. Su X, Paris M, Gi YJ, Tsai KY, Cho MS, Lin Y-L et al. TAp63 prevents premature aging by promoting adult stem cell maintenance. Cell Stem Cell 2009; 5: 64-75.

23. Rufini A, Tucci $P$, Celardo I, Melino G. Senescence and aging: the critical roles of p53. Oncogene 2013; 32: 5129-5143.

24. Talos F, Nemajerova A, Flores ER, Petrenko O, Moll UM. P73 supresses polyploidy and aneuploidy in the absence of functional p53. Mol Cell 2007; 27: 647-659.

25. Suh EK, Yang A, Kettenbach A, Bamberger C, Michaelis AH, Zhu Z et al. p63 protests the female germ line during meiotic arrest. Nature 2006; 444: 624-628.

26. Pozniak CD, Radinovic S, Yang A, McKeon F, Kaplan DR, Miller FD. An anti-apoptotic role for the p53 family member, p73, during developmental neuron death. Science 2000; 289 : 304-306.

27. Pozniak CD, Barnabe-Heider F, Rymar VV, Lee AF, Sadikot AF, Miller FD. p73 is required for survival and maintenance of CNS neurons. J Neurosci 2002; 22: 9800-9809.

28. Jacks T, Remington L, Williams BO, Schmitt EM, Halachmi S, Bronson RT et al. Tumor spectrum analysis in p53-mutant mice. Curr Biol 1994; 4: 1-7.

Supplementary Information accompanies this paper on Cell Death and Differentiation website (http://www.nature.com/cdd) 